وضعيت كنونى فلور ايران: راستهها و تيرههاى نهاندانهُ ايران مطابق با APG IV

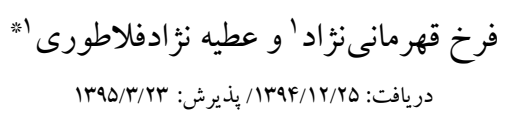

$$
\text { اخروه علوم گياهى، دانشكده علوم زيستى، دانشكاه خوارزمى، تهران }
$$
a.falatoury@gmail.com :مسئول مكاتبات

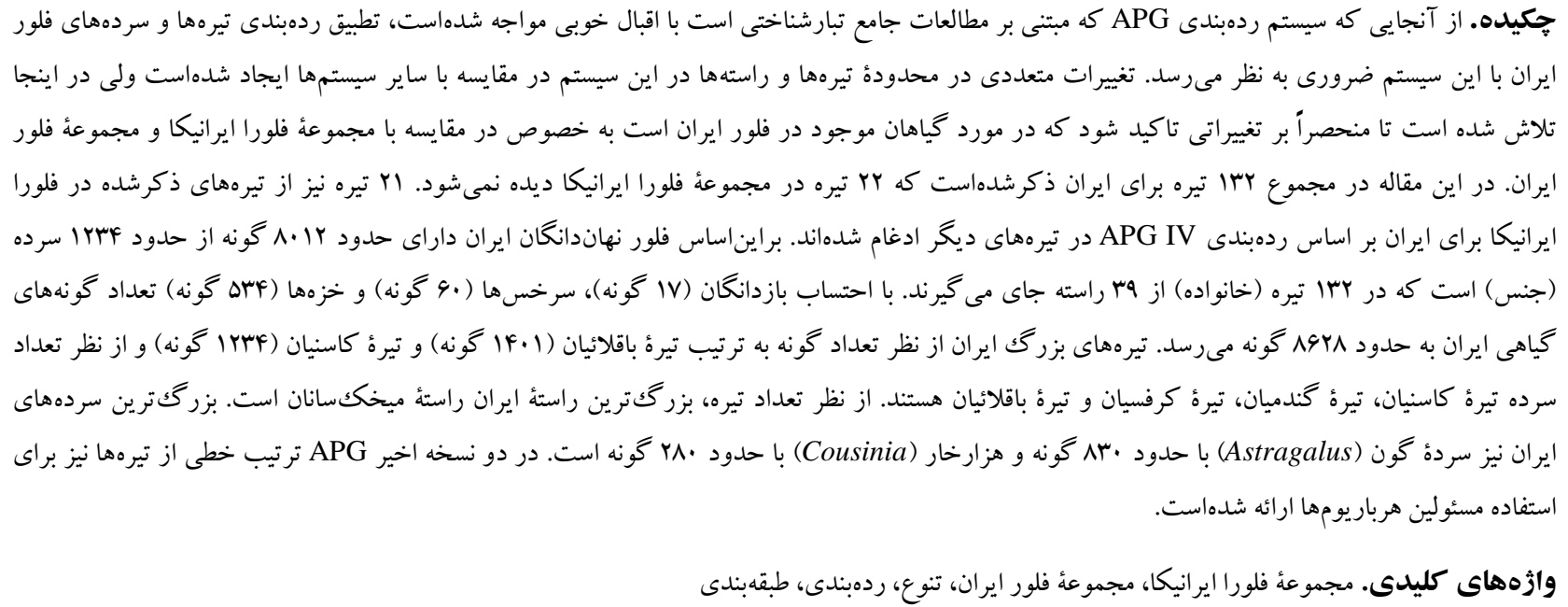

\title{
An update on the flora of Iran: Iranian angiosperm orders and families in accordance with APG IV
}

\author{
Farrokh Ghahremaninejad $^{1}$, Atiye Nejad Falatoury ${ }^{1 *}$ \\ Received 15.03.2016/ Accepted 13.06.2016
}

\begin{abstract}
${ }^{1}$ Department of Plant Sciences, Faculty of Biological Sciences, Kharazmi University, Tehran, Iran.
"Correspondent author: a.falatoury@gmail.com
\end{abstract}

\begin{abstract}
The increasing influence of APG classification system necessitates an update on taxa recorded in most regional floras including Iran. Many changes in circumscriptions of families and orders have occurred in APG in comparison with other classification systems. However, here we only attempt to emphasize on changes in the Iranian flora, especially in comparison with "Flora Iranica" and "Flora of Iran". Of the overall 132 family names which have been mentioned here, 22 families are not found in Flora Iranica. Based on the APG IV system, 21 families which had been mentioned in Flora Iranica for Iran should be merged with other families. Accordingly, the angiosperms of Iran comprise 8012 species, approximately 1234 genera and 132 families placed in 39 orders. Gymnosperms (17 spp.), ferns (60 spp.) and mosses (534 spp.) included, the number of plant species of Iran exceeds approximately 8628 species. The largest angiosperms families of Iran are Fabaceae (1401 spp.) and Asteraceae (1234 spp.) in terms of number of species, and Asteraceae, Poaceae, Apiaceae and Fabaceae in terms of number of genera. The largest angiosperm order of Iran in terms of family number is Caryophyllales. The largest genera of Iran are Astragalus with about 830 species and Cousinia with about 280 species. In the two latest versions of APG a linear sequence of families is provided to be used by herbarium curators.
\end{abstract}

Keywords. flora Iranica, flora of Iran, diversity, taxonomy, classification 


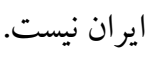

از آنجايى كه بيشبينى مىشود ردهبندى ارائهشده در نسخة اخير

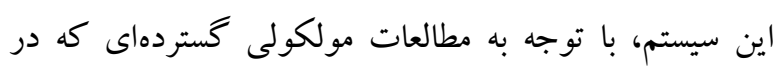

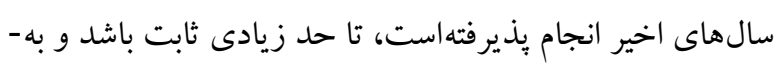

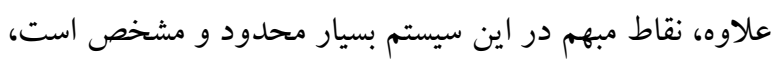

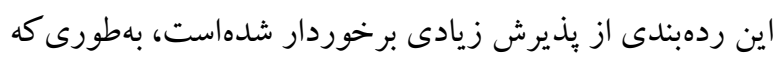

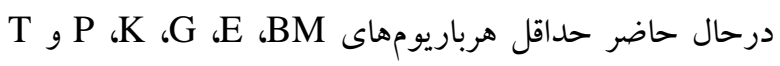
(مخفف اسامى هرباريومها براساس (Thiers, 2015 درحال مر تبسازى نمونه هاى خود براساس اين ردهبندى هستند.

نظر به نكات ذكرشده و همينطور با توجه به مطالعات متعدد

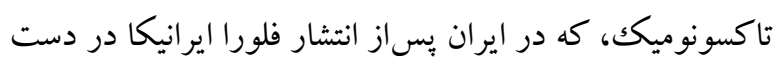

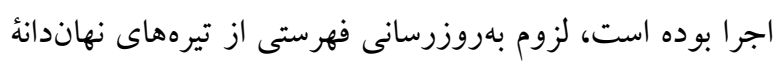

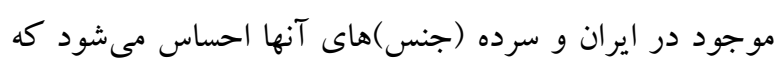

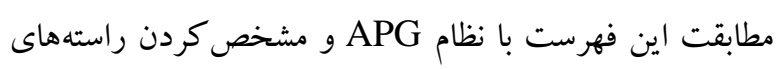
اين تيرهها مىتواند براى محققانى كه در آينده قصد انجام

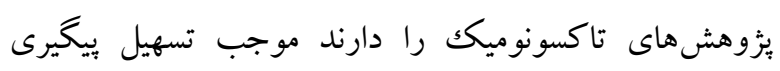

$$
\text { مطالعات مرتبط شود. }
$$

\section{مواد و روشها}

در اين نوشتار فهرست كاملى از سردهها، تيرهها وراستهاى

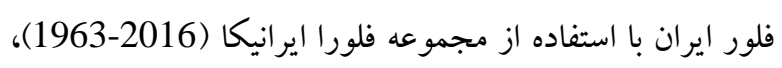

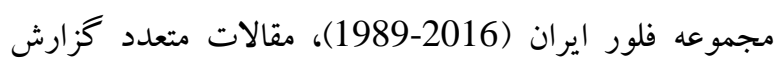

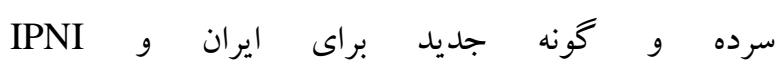
تهيه شدهاست. (http://www.ipni.org)

تمام سردهاى ذكرشده در فلورا ايرانيكا در اين فهرست ذكر

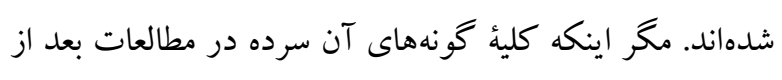

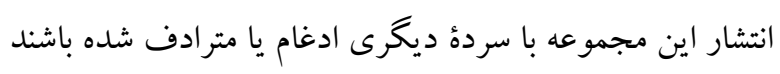

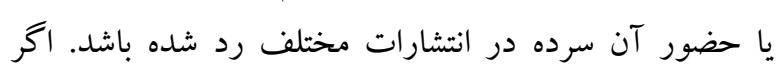

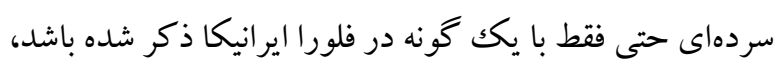

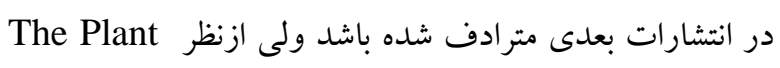
نام (http://www.theplantlist.org) List نام سرده ذكرشدهاست. سردهايى كه گونهاى با عنوان The Plant List Unressolved آمدهاند. براى اسامى فارسى جز در موارد استثنيى از مصويات
يثزوهشهاى آرايهناختى، ريختشناختى و مولكولى كه به-

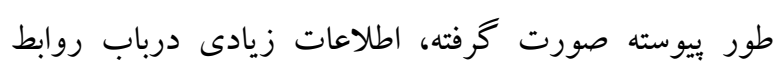

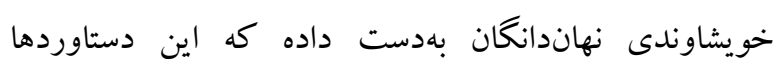

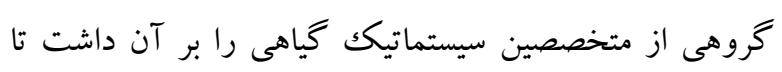

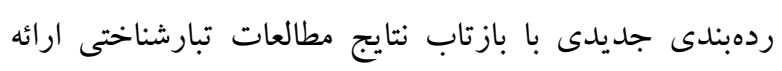

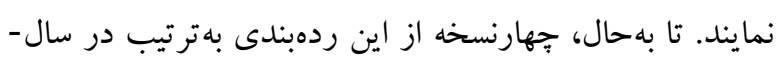

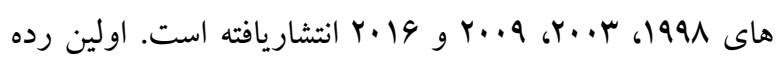
بندى كه اين گروه ارائه كردند عمدتاً در سطح راستها ها و صرفاً

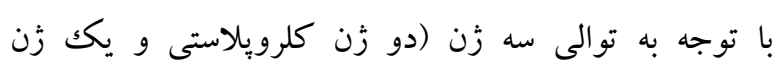

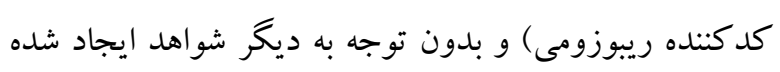

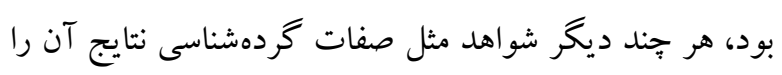
تأييد مى كرد (APG, 1998). در APG II بنج راسته جديد غالباً از تغيير سطح تيرهها به راسته

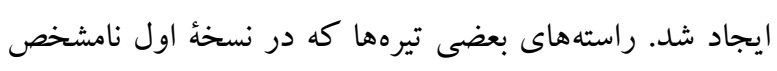
بود مشخص شد و تعدادى تيره در براكت، كه ادغام آنها با تيا

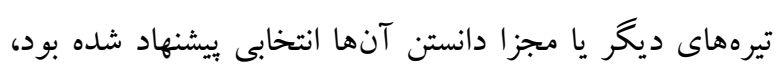
در نسخه دوم وجود داشتند (APG, 2003).

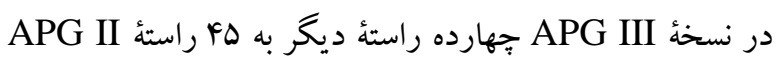
اضافه شد. محدوده و راستأ تعدادى از تيرهها در اين نسخه تغيير كرد، تيرههاى در براكت ادغام شدند و بنابراين، تعداد تيرهها از

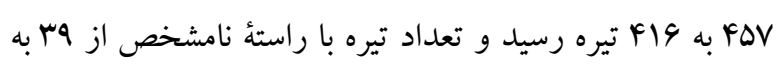
ا تيره كاهش يافت (APG, 2009). در نسخة APG IV تعداد راستهها با مشخص كردن راسته تيره-

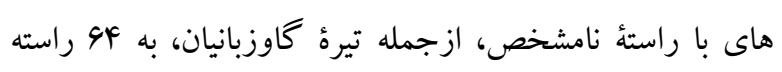

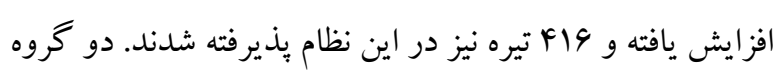

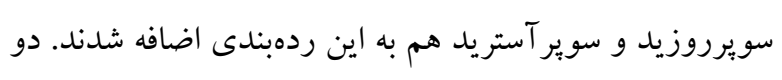
تيرة انكلى، كه بيشاز اين موقعيت آنها بهطور دقيق مشخص

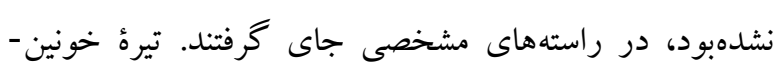

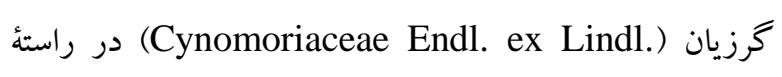

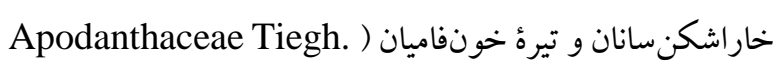
APG, ) در راستة كدوسانان قرار دادهشدند (ex Takht.

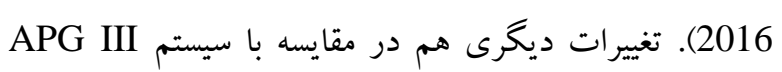


Hydrocharitaceae Juss. [ تختقورباغهايان (Najadaceae Juss.) آن ادغام شدهاست در ايران شش سرده دارد. تيرهُ نواريان (Zosteraceae Dumort.) تيره گوشابيان (Potamogetonaceae Bercht. \& J.Pres1) در ايران جهار سرده دارد كه دو سردة آن بيش از اين در تيره

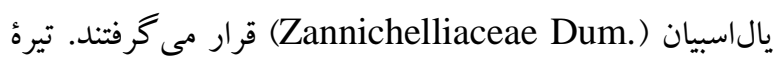
Cymodoceaceae Vines ييش از اين متعلق به تيره يالاسبيان بودند.

0. راستُ سوسنسانان (Liliales Perleb)

اين راسته داراى سه تيره در ايران است. تيرة سوسنيان (Liliaceae Juss.)

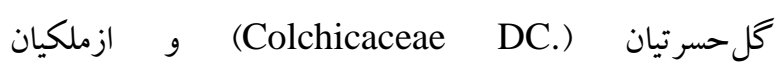
كه هر كدام يكك سرده در فلور ايران (Smilacaceae Vent.) دارند. هر دو تيرة مذكور در فلورا ايرانيكا متعلق به تيرة سوسنيان (Liliaceae) بودند.

7. راستُ مارجوبهسانان (Asparagales Link)

اين راسته داراى شش تيره در ايران است. تيرهُ ثعلبيان

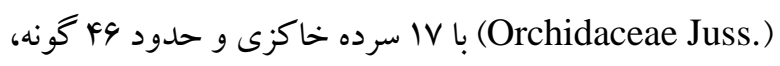
تيرةُ مونوتييكك خياركيان (Ixioliriaceae Nakai) با يك سرده و يكك گونه كه از . Amaryllidaceae J.St.-Hil جدا شده است و تيرهُ زنبقيان (Iridaceae Juss.) با ينج سرده در ايران براكنش دارند. تيره سريشيان (Asphodelaceae Juss) If (Asparagaceae Juss.) سه سرده و تيرة مارجوبهايان

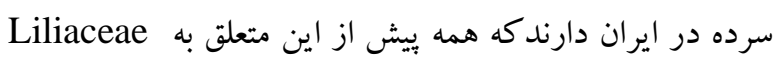

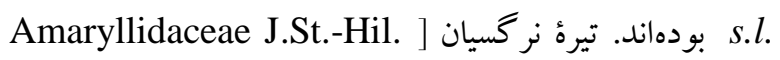
[(incl. Alliaceae Borkh.)

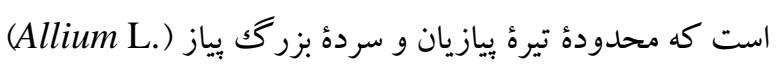

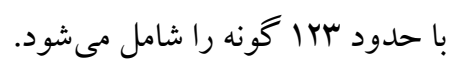

Y. راستهٔ بركىبيدىسانان ( Commelinales Mirb. ex

(Bercht. \& J.Presl

Pontederiaceae ) اين راسته داراى يك تيره يعنى غلافيان

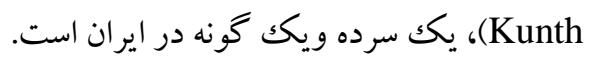

فرهنگستان زبان و ادب فارسى جمهورى اسلامى ايران (Terminology Departmant, 2003-2015)

است (جدول (، شكل (). نتايج و بحث

ا. راستهُ نيلوفر آبىسانان ( Nymphaeales Salisb. ex Bercht. \& J.Presl)

اين راسته يكك تيره در ايران دارد. تيرهُ نيلوفرآبيان (Nymphaeaceae Salisb.) Nelumbo ) براساس مطالعات فيلوزنى سردة ثعلهباقلا كه يِشاز اين متعلق به اين تيره بود، از آن جدا و تيرة (Adans. مستقلى در نظر كرفته مى شود.

ما منولئيدها (Magnolids)

r. راستة فلفلسياهسانان (Piperales Bercht. \& J.Presl) اين راسته يكك تيره در ايران دارد. تيرهُ زرآونديان (Aristolochiaceae Juss.) در ايران است.

\section{تكتلِهاىها (Monocots)}

('. اين راسته يكك تيره در ايران دارد. تيرة مونوتييك Acoraceae Martinov

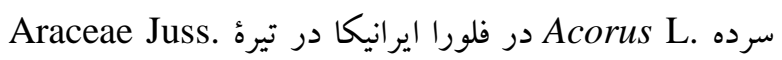
قرار داشت، ولى مطالعات جديد اين سرده را از تيره مذكور

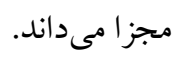

Alismatales R.Br. ex ) ع. راستؤ بارهنك آبعسانان (Bercht. \& J.Presl

اين راسته داراى هفت تيره در ايران است. تيرهُ شييوريان [Araceae Juss. (incl. Lemnaceae S.F.Gray)] سرده در ايران يُراكندهاست كه سه سرده آن يِيش از اين متعلق به تيرة عدسك آبيان (Lemnaceae) بودند. تيرهٔ بارهنك آبيان سه سرده و تيرة مونو تيييك هزارنى (Alismataceae Vent.) ايان (Butomaceae Mirb.) يك گُونه در ايران دارند. تيرة 


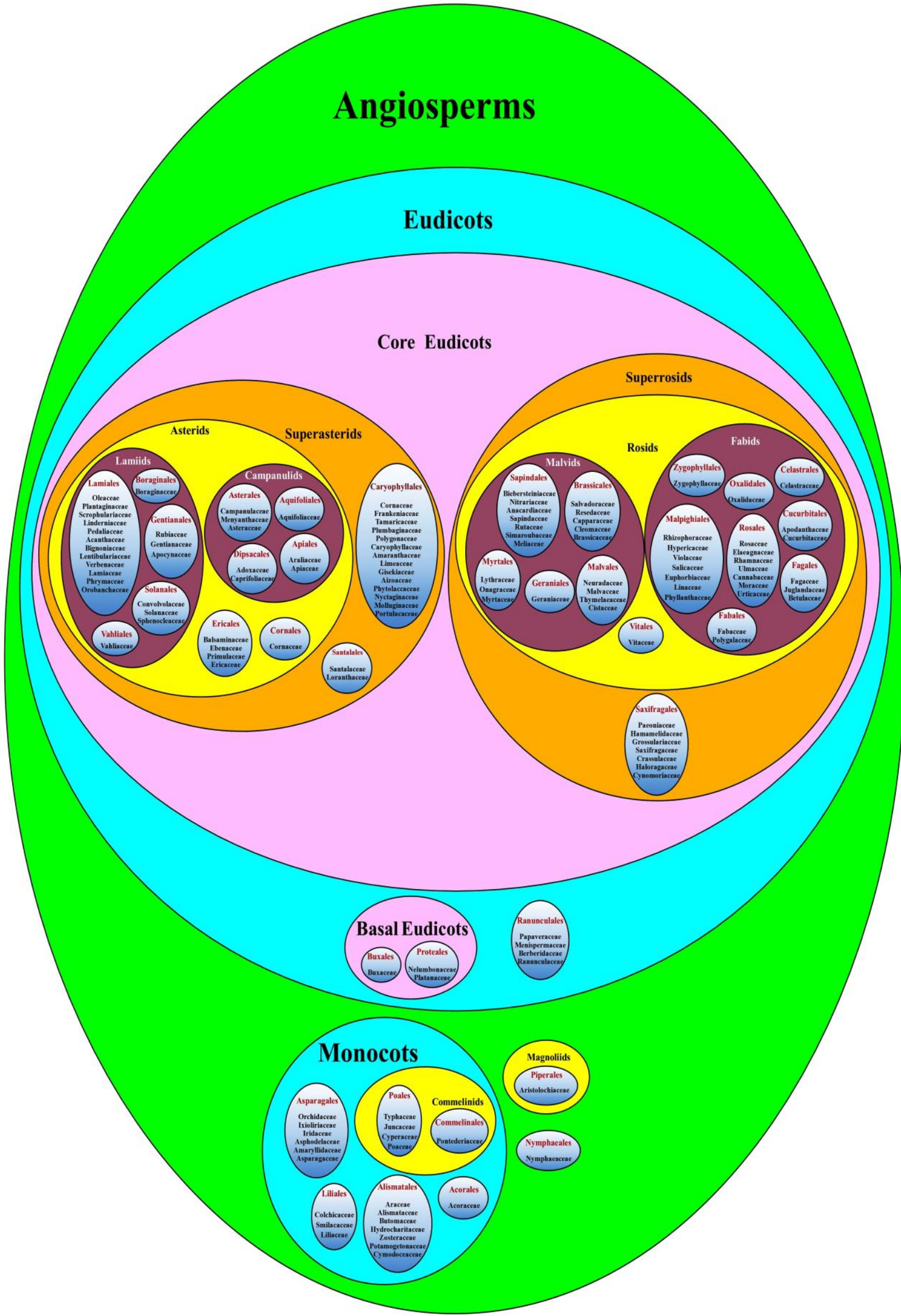

شكل ا - تيرهها و راستههاى نهاندانكان ايران بر اساس سيستم APG IV.

Fig. 1. Angiosperm families and orders of Iran in accordance with APG IV. 
اين راسته داراى يك تيره شمشاديان (Duxaceae Dumort.

Saxifragales Bercht. \& ) باستة خاراشكنسان (J.Presl

اين راسته داراى هفت تيره در ايران است. تيرهٔ مونوتيبيك كل صدتومانيان (Paeoniaceae Raf.) با دو گُنه كه در فلورا

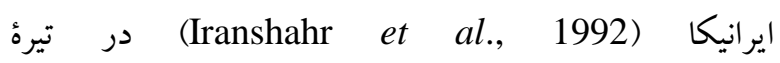
Ranunculaceae

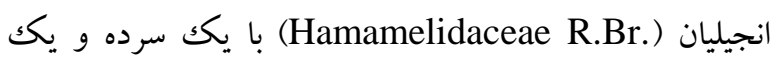

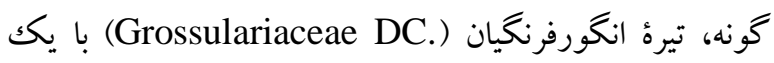

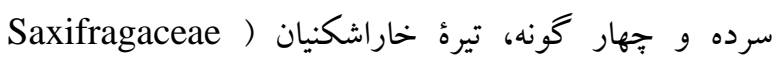
با يكك سرده و حدود ده گونه، تيره كل تازيان (Juss. (Crassulaceae J.St.-Hil.) تيرهُ هزاربر گيان (Haloragaceae R.Br.) و تيرة مونو تيبيك

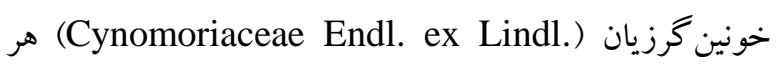
كدام با يكك سرده در ايران بر اكندهاند.

\section{رزيدها (Rosids)}

Vitales Juss. ex Bercht. \& ) با. راستهُ انكورسانان (J.Presl

اين راسته داراى يكك تيره به نام انغوريان (Vitaceae Juss) با

$$
\text { دو سرده در ايران است. }
$$

ع ع. راستهُ قيجسانان (Zygophyllales Link)

اين راسته داراى يك تيره به نام قيجيان ( Zygophyllaceae (R.Br.

10. راستةُ باقلاسانان (Fabales Bromhead)

اين راسته با دو تيره در ايران حضور دارد. تيره باقلائيان

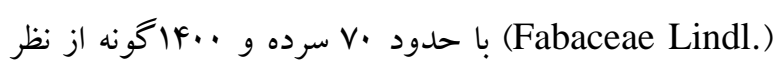

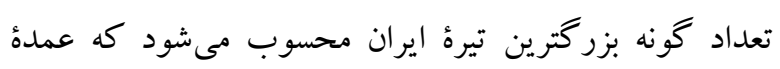
كونههاى آن مربوط به سرده گون (Astragalus L.) است. اين سرده با حدود ·rم كونه (Ghahremaninejad, 2015)

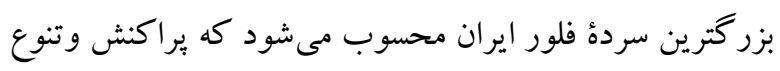

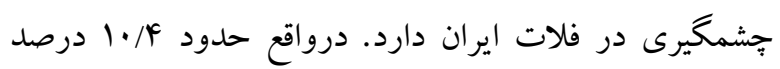

1. 1 راستهُ كندمسانان (Poales Small)

اين راسته داراى جهار تيره در ايران است. تيرة لوئيان

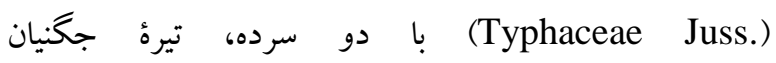
(Cyperaceae Juss.) با دو سرده متعلق به اين راستهاند. (Juncaceae Juss.) همجنين تيرهُ گَندميان (Poaceae Barnhart) از اين راسته از إن

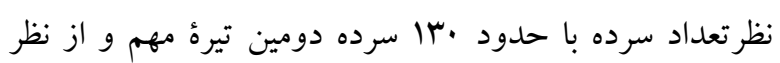

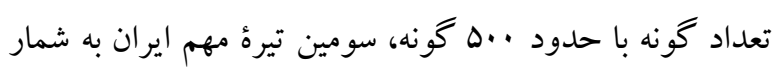
مى آيد.

\section{دولٍهاى هاى حقيقى (Eudicots)}

جanunculales Juss. ex Bercht. \& ) واستة آلالهسانان

(J.Presl

اين راسته داراى جهار تيره در ايران است. تيرهُ شقايقيان [Papaveraceae Juss. (incl. Fumariaceae Marquis)] دربر گيرنده تيره شاهترهايان (Fumariaceae) با هفت سرده،

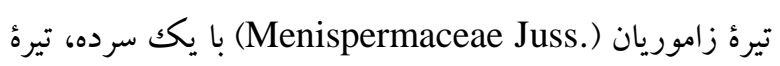

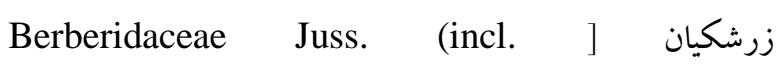
با جهار سرده كه سه تا از آنها (Podophyllaceae DC.) ييش از اين در تيرة Podophyllaceae جاى داشتند و تيرة

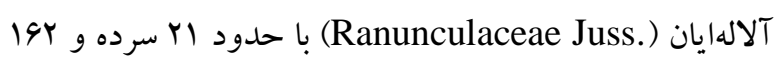
كونه، اعضاى اين راسته در اير ان را تشكيل مىدهند.

•l. Proteales Juss. ex Bercht. \& ) קاستُ جنارسانان (J.Presl

اين راسته داراى دو تيره در ايران است. تيرهٔ مونو تيييك ثعله -

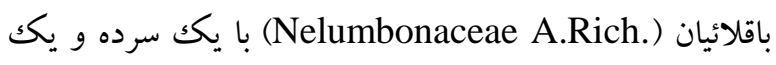

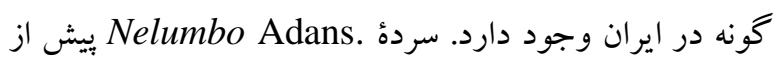

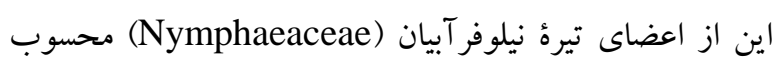

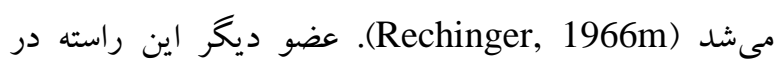
ايران تيره مونوتييكك جناريان (Platanaceae T.Lestib.) است كه با يك گونه . Platanus orientalis L. در ايران ير اكندهاست كه به احتمال زياد از گذشتئ كاشته شده و در حال حاضر داراى جمعيت هاى طبيعى نيز است. 1). راستهُ شمشادسانان (Buxales Takht. ex Reveal) 
در ايران است كه در فلورا ايرانيكا (Rechinger, 1978h) در

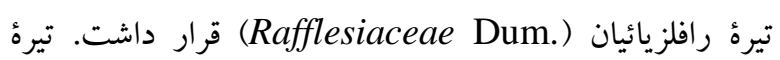
كدوئيان (Cucurbitaceae Juss) با ينج سرده در ايران ير اكندهاست.

9 1. راستة كوشوارهسانان (Celastrales Link) اين راسته داراى يكك تيره در ايران است. تيره گوشواركيان [Celastraceae R.Br. (incl. Parnassiaceae Gray)] ايران سه سرده دارد كه يكى از آنها در فلورا ايرانيكا (Schönbeck-Temesy, 1966b) Parnassiaceae

Oxalidales Bercht. \& ) راستهُ شبدرتوشكسانان (J.Presl

اين راسته داراى يكك تيره در ايران است. تيره شبدرترشكيان

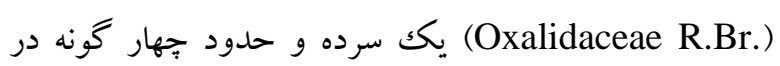

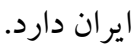

Malpighiales Juss. ex Bercht. ) آr. راستهُ مالِينَى سانان

(\& J.Presl

اين راسته داراى هفت تيره در ايران است. تيره جندليان يكك سرده و تيرة كلراعيان (Rhizophoraceae Pers.)

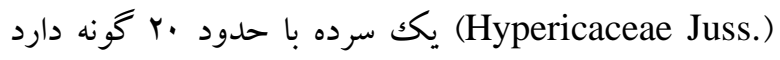
كه در فلورا ايرانيكا (Robson, 1968) در تيرة: Clusiaceae Lindl.

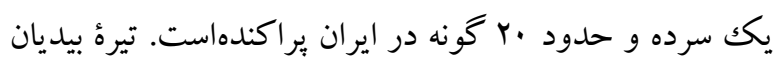
(Salicaceae Mirb.) : جهار سرده و تيرة كتانيان (Euphorbiaceae Juss.) يكك سرده در ايران دارند. تيرة تئرة (Linaceae DC. ex Perleb) نازبيابانيان (Phyllanthaceae Martinov) يك سرده در درد درد تيره

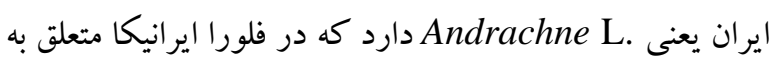
فرفيونيان بودهاست ( Rechinger \& Schiman-Czeika,

(1964

Trraniales Juss. ex Bercht. ) راستهُ شمعدانىسانان

(\& J.Presl
كونههاى گياهى فلور نهاندانگان ايران مربوط به اين سرده Polygalaceae ( است. تيره ديخر اين راسته تيره شير آوريان

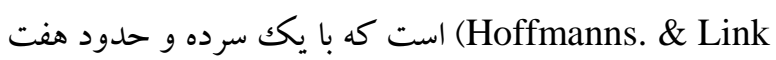
كونه در ايران براكندهاست.

17 . راستة گلسرخ سانان (Rosales Bercht. \& J.Presl) اين راسته داراى هفت تيره در ايران است. تيرء گلسرخيان با حدود Fraceae Juss.) تيرة اين راسته در ايران است. شايان ذكر است در نتيجه

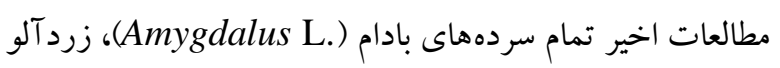
(Armeniaca Scop.) و هلو Padus Mill. ،(Lauro-cerasus Duhamel) مترادف سردة آلو (Prunus Lersica Mill.) نظر گرفته مىشوند. تيرهُ سنجديان (Elaeagnaceae Juss.) دوسرده، تيره عنابيان (Rhamnaceae Juss) ينج سرده، تيرة نارونيان (Ulmaceae Mirb.) دو سرده، تيرة شاهدانهايان

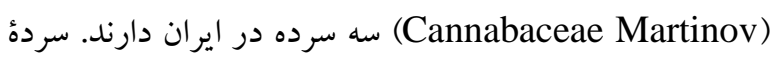
داغداغان (Celtis L.) براساس مطالعات تبارشناختى از تيره نارونيان به تيرة شاهدانهايان منتقل شدهاست. تيرههاى ديخر اين

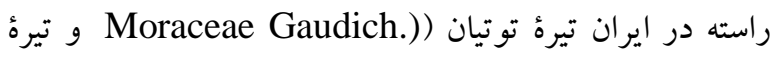
كزنهايان (Urticaceae Juss) هر كدام با سه سرده هستند. Yl Y. راستهُ راشسانان (Fagales Engl) اين راسته داراى سه تيره در ايران است. تيرهُ راشيان Juglandaceae ) و تيرة گردونئيان (Fagaceae Dumort.) هركدام با دو سرده و تيرة توسكاييان (DC. ex Perleb [Betulaceae Gray (incl. Corylaceae Mirbel)] جهار سرده در ايران بر اكندهاند. سردهاى ممرز ( Carpinus

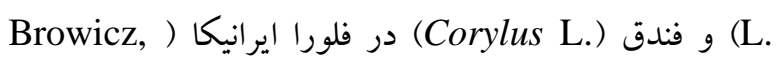

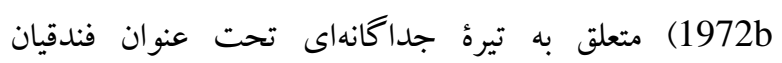
بودند. (Corylaceae)

11. راستؤ كدوسانان ( Cucurbitales Juss. ex Bercht. \& (J.Presl اين راسته داراى دو تيره در ايران است. تيره خونفاميان (Apodanthaceae Tiegh. ex Takht.) 
شامل حدود سا سرده و •^ گونه در ايران [Tiliaceae Juss.) است. تيرهٔ مازريونيان (Thymelaeaceae Juss) با ينج سرده و تيرة گل آفتابيان (Cistaceae Juss) با دو سرده در ايران

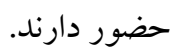

7r. راستة كلمسانان (Brassicales Bromhead)

اين راسته داراى ينج تيره در ايران است. تيره مسواكيان يك سرده، تيره اسبر كيان (Salvadoraceae Lindl.) سه سرده و تيرة: كبريان (Resedaceae Martinov) سه سرده در ايران دارند. تيرة علف- سيرة سكرديات (Capparaceae Juss.) ماريان (Cleomaceae Bercht. \& J.Presl) با يكك سرده و كونه در ايران حضور دارد كه بيش از اين متعلق به كبريان

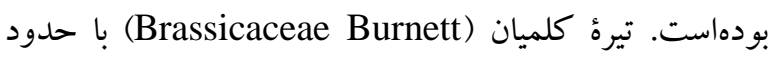

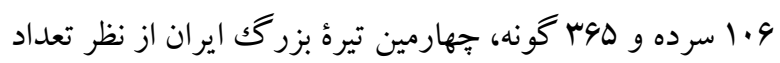
سرده و هفتمين از نظر تعداد گونه است.

Santalales R.Br. ex Bercht. \& ) راستة صندل

(J.Pres1

اين راسته داراى دو تيره در ايران است. تيره صندليان [Santalaceae R.Br. incl. Viscaceae Batsch] دارواشيان (Viscaceae) در آن ادغام شدهاست با جهار سرده

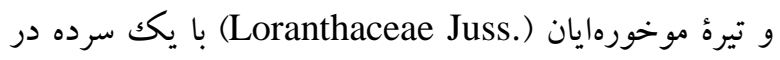
ايران بر اكندهاند.

Ar. Caryophyllales Juss. ex ) راستة ميخكسانان

(Bercht. \& J.Presl

اين راسته داراى جهارده تيره و يكى از دو راستهُ بزر گك ايران از

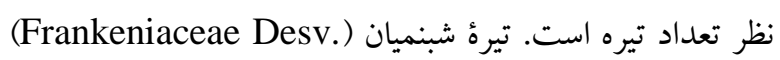

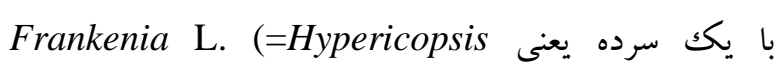
در ايران وجود دارد. تيرة (Olson et al., 2003) Boiss.) گزيان (Tamaricaceae Link) با سه سرده، تيره كلاهميرحسنيان (Plumbaginaceae Juss) با شش سرده، تيرة علف هفتبنديان (Polygonaceae Juss) با نه سرده و تيرة

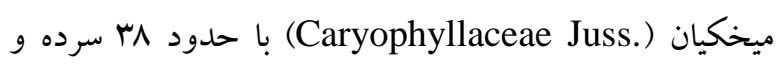

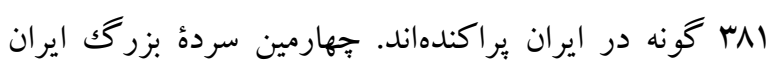
يعنى .Silene L با حدود 1.9 كونه متعلق به تيرهُ ميخكيان
اين راسته داراى يكك تيره در ايران است. تيرهُ شمعانيان (Geraniaceae Juss.)

$$
\text { دارد. }
$$

Myrtales Juss. ex Bercht. \& ) ب. راستة موردسانان (J.Presl

اين راسته داراى سه تيره در ايران است. تيره حنائيان Lythraceae J.St.-Hil. (incl. Punicaceae Horan. \& ] [Trapaceae Dum.) مطالعات تبارشناختى دو تيره اناريان و سه كنجهخيزيان در تيره حنائيان ادغام شدهاند. تيرة گلمغرييان (Onagraceae Juss)

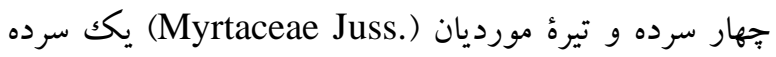
در ايران دارند.

عapindales Juss. ex Bercht. \& ) ع. راستة افراسانان

(J.Presl

اين راسته داراى هفت تيره در ايران است. تيره مونوتييكك

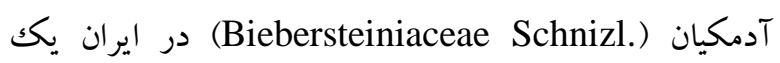

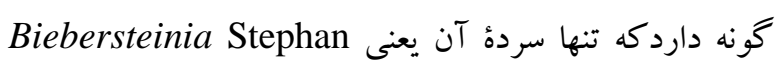
ييش از اين از شمعدانيان برشمرده مىشد. تيره قرهداغيان كه هر جهار سردهُ موجود در ايران (Nitrariaceae Lindl.) آن ييش از اين در تيرهُ قيجيان قرار مى گرفت. تيرهُ يستهايان

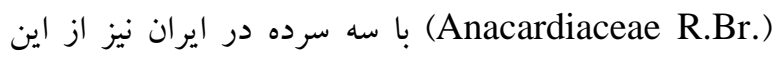
Sapindaceae Juss. (incl. ] راسته است. تيره ناتر كيان آنسان [Aceraceae Juss.) جديد اين تيره شامل تيرهُ افرائيان (Aceraceae) نيز مىشود. تيرة سدابيان (Rutaceae Juss.) سه سرده، تيرء عرعريان يكك سرده مهاجم و تيرة زيتون- (Simaroubaceae DC.) تلخيان (Meliaceae Juss) دوسرده درايران دارند.

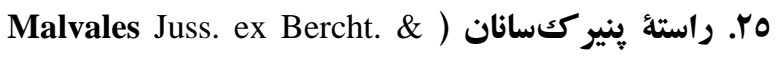
(J.Presl

اين راسته داراى جهار تيره در ايران است. تيره تكمهشنيان

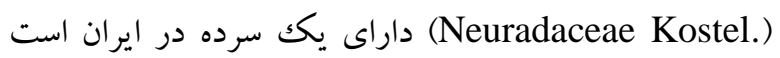
كمه بيش از اين در تيرة گل سرخيان قرار دادهمى شد ( Browicz

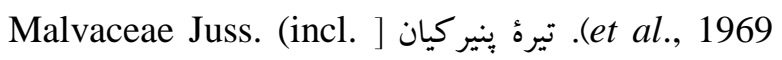


سرده در ايران دارد. مطالعات اخير تبارشناختى على رغم

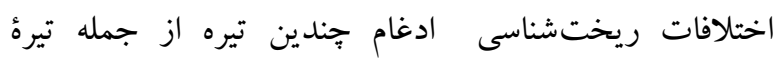

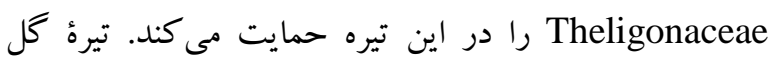
سياسيان (Gentianaceae Juss.) در ايران پِنج سرده دارد.

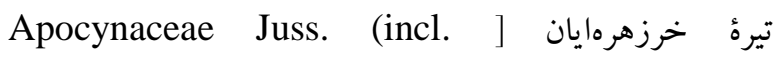
[Asclepiadaceae R.Br.)

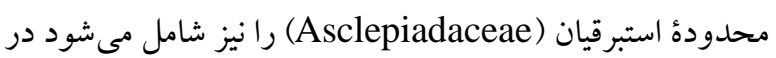

$$
\text { ايران حدود } 19 \text { سرده دارد. }
$$

rraginales Juss. ex Bercht. ) راستة كاوزبانسانان

(\& J.Pres1

اين راسته داراى يك تيره بزرگك در ايران است. تيره كاوزبانيان حدود ها سرده و • (Boraginaceae Juss.) ايران دارد و از نظرتعداد سرده هشتمين و از نظر تعداد گونه

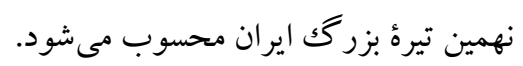

rr- راستة واهليال (Vahliales Doweld)

اين راسته داراى يك تيره در ايران است. تيرة مونوتيبيك

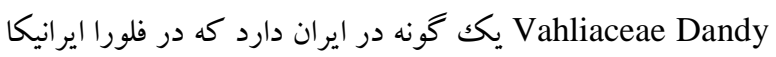

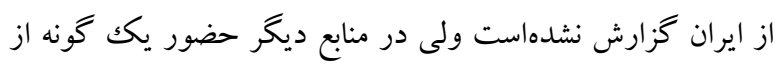
آن در ايران تاييد شدهاست (Thiv, 2016).

Solanales Juss. ex Bercht. \& ) راستهُ بادنجانسانان

(J.Presl

اين راسته داراى سه تيره در ايران است. تيرهُ بِيجِيان [Convolvulaceae Juss. Incl. Cuscutaceae Dum.] كه براساس مطالعات تبارشناختى محدودة تيره سسيان

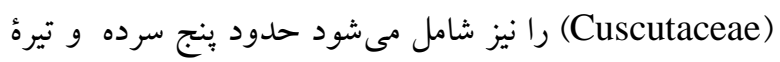
بادنجانيان (Solanaceae Juss) هشت سرده در ايران دارند.

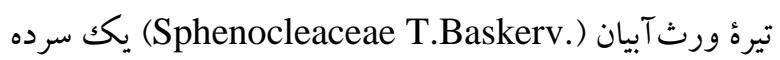

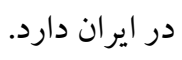

م-ro راستة نعناسانان (Lamiales Bromhead)

اين راسته داراى دوازده تيره در ايران است و دومين راسته Oزرگك ايران از نظر تعداد تيره است. تيرهٔ زيتونيان ( Oleaceae ينج سرده در ايران دارد. تيرة

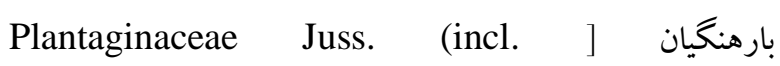

است. اين تيره ينجمين تيره بزرگك ايران از نظر تعداد گونه

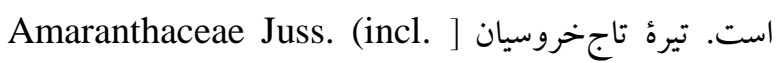

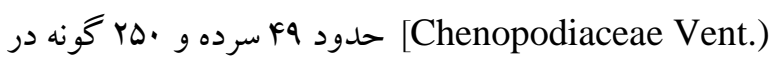
ايران دارد. مطالعات تبارشناختى ادغام تيرة اسفناجيان را با اين تيره حمايت مى كند. تيرة Lophiocarpaceae Doweld \& Reveal Reveal مونوتيبك Gisekiaceae Nakai هر كدام با يك سرده در

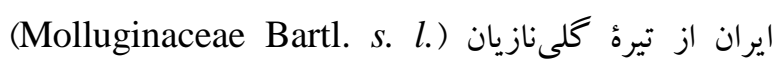
جداشدهاند. تيرهٔ علففرشيان (Aizoaceae Martinov) با سه تهان سرده، تيره سرخاب كوليان (Phytolaccaceae R.Br.) با يكك

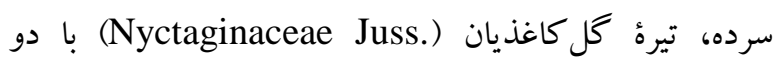

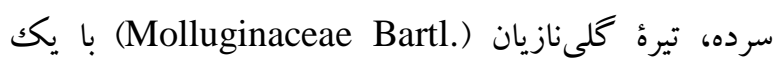

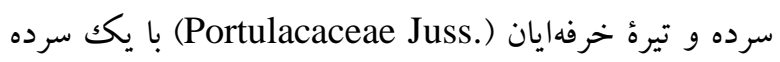
در ايران حضور دارند.

(Asterids) (آستريدها

9. واستؤ ذغال اختهسانان (Cornales Link)

اين راسته داراى يك تيره در ايران است. تيرهُ ذغالاختهايان يكك سرده درايران دارد. (Cornaceae Bercht. \& J.Presl)

• • •. راستهُ خلنكَسانان (Ericales Bercht. \& J.Presl) اين راسته داراى جهار تيره در ايران است. تيرء گلبىصبريان يك سرده، تيرة خرمالوئيان (Balsaminaceae A.Rich.) يك سرده و تيرة : يامجاليان (Ebenaceae Gürke ) نه سرده در ايران (Primulaceae Batsch ex Borkh.) Ericaceae Juss. (incl. ] دارند. تيرة خلنكيان [Monotropaceae Nutt. \& Pyrolaceae Dum.) احتساب دو سردهاى كه از برگك امروديان (Pyrolaceae) و

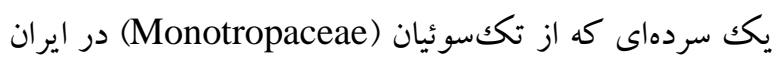
وجود دارد و با توجه به ادغام اين دو تيره با خلنخيان، جهار

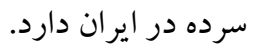

آ. راستة علسياسىسانان ( Gentianales Juss. ex (Bercht. \& J.Presl اين راسته داراى سه تيره در ايران است. تيره روناسيان Ir [Rubiaceae Juss. (incl. Theligonaceae Dum.)] 
اين راسته داراى يك تيره در ايران است. تيره خاسيان يكك سرده و گونه (Aquifoliaceae Bercht. \& J.Presl)

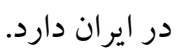

\section{(Asterales Link) راستة كاسنىسانان}

اين راسته داراى سه تيره در ايران است. تيره گل استكانيان (Campanulaceae Juss.) تيرء شبدرباتلاقيان (Menyanthaceae Dumort.) دو سرده در ايران دارد كه در فلورا ايرانيكا هر دو در تيرة كل سياسيان (Gentianaceae) تيرء كاسنيان (Asteraceae Bercht. \& J.Pres1) با حدود

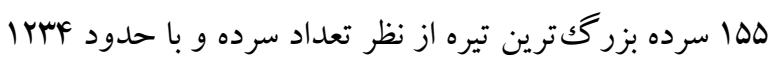
كونه دومين تيره از نظر تعداد گونه در ايران است.

Dipsacales Juss. ex ) راستة خواجهباشىسانان (Bercht. \& J.Pres1

اين راسته داراى دو تيره در ايران است. تيره آ Adoxaceae

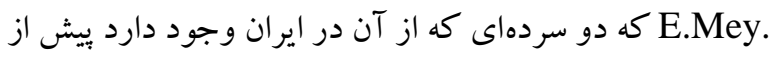
اين در تيرة ديخر اين راسته يعنى تيرة آقطيان (Caprifoliaceae Juss.) Caprifoliaceae Juss. (incl. Dipsacaceae Juss., ] Morinaceae J.G.Agardh \& Valerianaceae [Batsch)

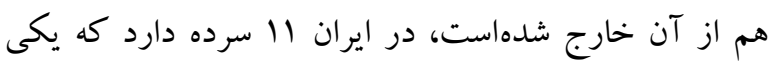

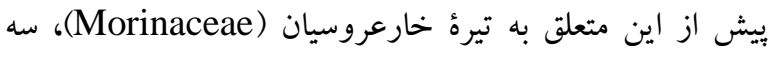

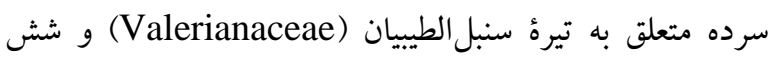
سرده متعلق به تيرة خواجهباشيان (Dipsacaceae) بوده است.

qج- راستة كرفسسانان (Apiales Nakai)

اين راسته داراى دو تيره در ايران است. تيره عشقهايان با دوسرده در ايران كه يكى از آنها (Araliaceae Juss.) ييش از اين متعلق به تيرة ديخر اين راسته يعنى كرفسيان بود. تيره كرفسيان (Apiaceae Lindl.)

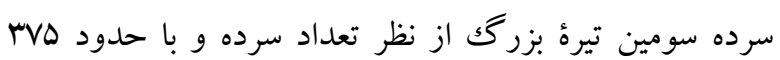
گونه ششمين تيره بزر گك ايران از نظر تعداد گونه است.
Callitrichaceae Link, Globulariaceae DC. \& كه با محدودهى وسيع جديدش (Hippuridaceae Link.) تعداد زيادى از سردهاى تيرة گلميمونيان و تيرههاى ستارهآبيان (Callitrichaceae)، كلوبو لارياسه (Globulariaceae)

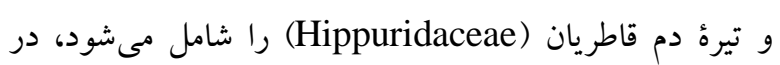

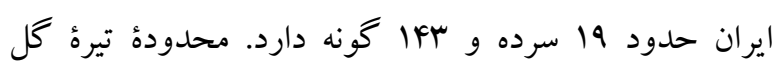
ميمونيان (Scrophulariaceae Juss) با مطالعات تبارشناختى اخير بسيار محدود شده و تعداد زيادى از سردههايى كه سابق بر اين در اين تيره جاى داشتند به تيرههاى ديخر از جمله تيره

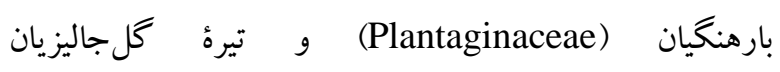
منتقل شدهاند. اين تيره هماكنون دو

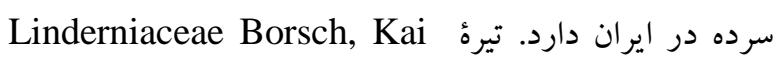
Pedaliaceae ) وتيره كنجديان Müll. \& Eb.Fisch.

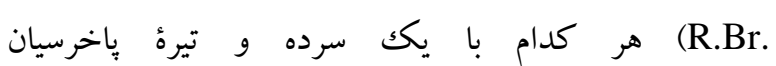
Acanthaceae Juss. (incl. Avicenniaceae Endl. Ex ] [Schnizl. شدهاست با سه سرده در ايران يراكندهاند. تيرهُ بيجاناريان يك سرده، تيرة علف انبانيان (Bignoniaceae Juss.) يكك سرده و تيره شاهيسنديان (Lentibulariaceae Rich.) (Verbenaceae J.St.Hil.)

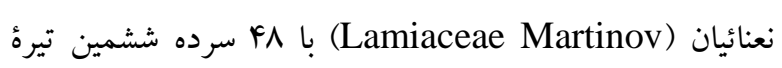

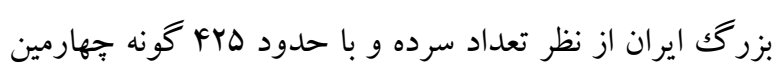

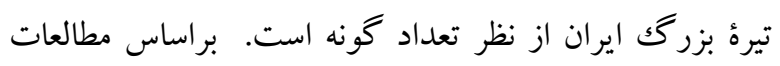

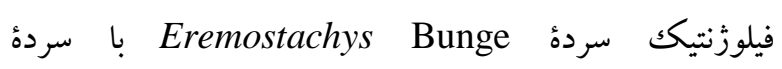
Phlomoides Moench

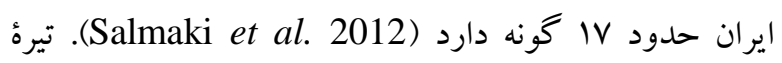
يكك سرده در ايران دارد كه در Phrymaceae Schauer

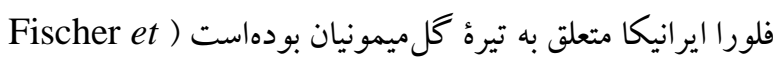

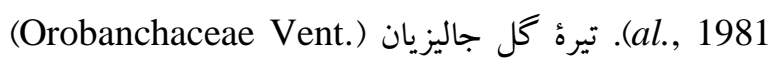

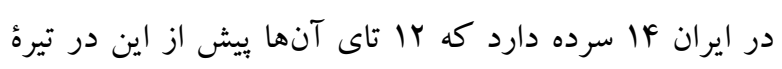
كل ميمونيان قرار دادهمى إندند.

جr- راستهُ خاسسانان (Aquifoliales Senft) 


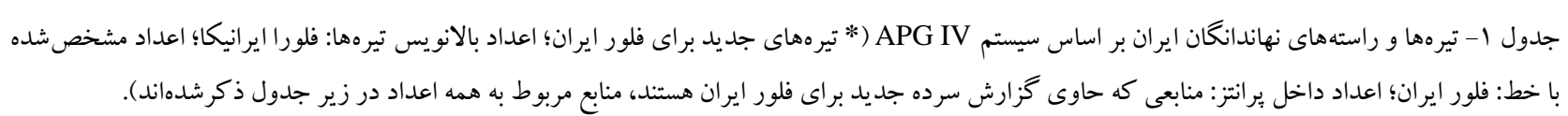

Table 1. Angiosperm families and orders of Iran in accordance with APG IV (* New family for the flora of Iran; Superscript numbers: Flora Iranica; Under lined numbers: Flora of Iran; Numbers in parenthesis: References includes new genus records for Iran, references of all numbers stated under the table).

\begin{tabular}{|c|c|c|c|}
\hline & Family & $\begin{array}{l}\text { Family name in } \\
\text { Persian and I.P. } \\
\text { alphabets }\end{array}$ & Genus/Genera \\
\hline 1 & $\begin{array}{l}\text { Acanthaceae }^{24,131, \underline{78}} \\
\text { (incl. Avicenniaceae) } \\
\text { [Lamiales] }\end{array}$ & $\begin{array}{l}\text { pa.khers.iyan } \\
(\text { ) }\end{array}$ & Acanthus $^{24}$, Avicennia $^{131, \underline{78}}$, Blepharis $^{24}$ \\
\hline 2 & $\begin{array}{l}\text { Acoraceae }^{* 3, \underline{2}} \\
\text { [Alismatales] }\end{array}$ & $\begin{array}{l}\text { barg.shamshir.iyan } \\
\text { (برك شمشيريان) }\end{array}$ & Acorus $^{3, \underline{2}}$ \\
\hline 3 & $\begin{array}{l}\text { Adoxaceae } * 10, \underline{13} \\
\text { [Dipsacales] }\end{array}$ & $\begin{array}{l}\text { bodagh.iyan } \\
\text { (بداغيان) }\end{array}$ & Sambucus ${ }^{10, \underline{13}}$,Viburnum $^{10, \underline{13}}$ \\
\hline 4 & $\begin{array}{l}\text { Aizoaceae }^{113,44} \\
\text { [Caryophyllales] }\end{array}$ & $\begin{array}{l}\text { alaefforsh.iyan } \\
\text { (علف فرشيان) }\end{array}$ & Aizoon, Mesembryanthemum, Zaleya \\
\hline 5 & $\begin{array}{l}\text { Alismataceae }^{78} \\
\text { [Alismatales] }\end{array}$ & $\begin{array}{l}\text { barhaeng.ab.iyan } \\
\text { (بارهنك آبيان) }\end{array}$ & Alisma $^{78}$, Damasonium $^{78}$, Sagittaria $^{78}$ \\
\hline 6 & 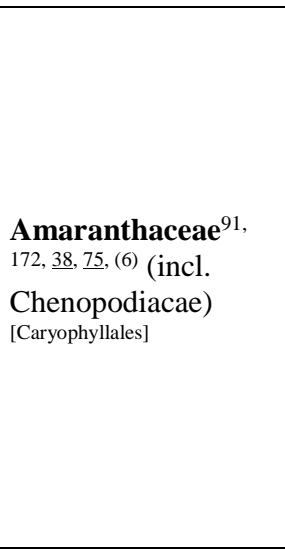 & $\begin{array}{l}\text { Taj.khurus.iyan } \\
\text { (تاج خروسيان) }\end{array}$ & 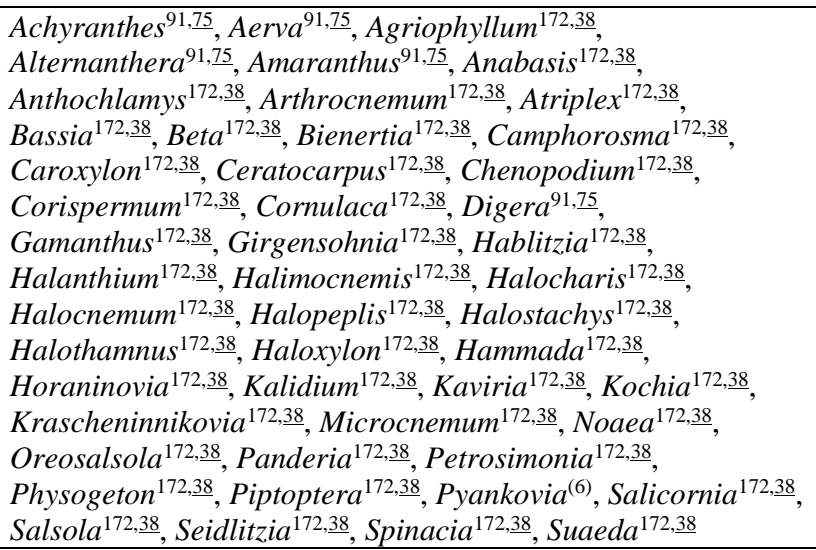 \\
\hline 7 & $\begin{array}{l}\text { Amaryllidaceae }^{67,76,} \\
\underline{47} \\
\text { (incl. Alliaceae) } \\
\text { [Asparagales] }\end{array}$ & $\begin{array}{l}\text { narges.iyan } \\
\text { (نرگسيان) }\end{array}$ & 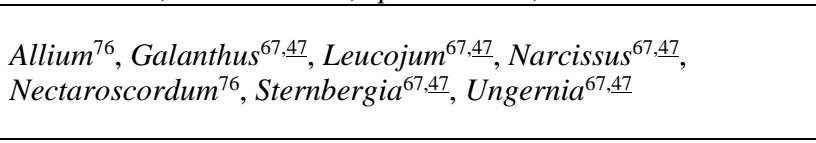 \\
\hline 8 & $\begin{array}{l}\text { Anacardiaceae }{ }^{63, \underline{3}} \\
\text { [Sapindales] }\end{array}$ & $\begin{array}{l}\text { peste.iyan } \\
\text { (يستهايان) }\end{array}$ & Cotinus, Pistacia, Rhus \\
\hline 9 & $\begin{array}{l}\text { Apiaceae }^{162,} \underline{54} \\
\text { [Apiales] }\end{array}$ & $\begin{array}{l}\text { kaercefs.iyan } \\
\text { (كرفسيان) }\end{array}$ & $\begin{array}{l}\text { Actinolema, Albovia, Alococarpum, Ammi, Anethum, } \\
\text { Anisosciadium, Angelica (=Xanthogalum), Anthriscus, } \\
\text { Aphanopleura, Apium, Artedia, Astrantia, Astrodaucus, Azilia, } \\
\text { Berula, Bifora, Bilacunaria, Bunium, Bupleurum, } \\
\text { Calyptrosciadium, Carum, Caucalis, Centella, Peucedanum } \\
\text { (=Cervaria), Chaerophyllum, Chaetosciadium, } \\
\text { Chamaesciadium, Conium, Coriandrum, Cuminum, } \\
\text { Cymbocarpum, Daucus, Demavendia, Dicyclophora, } \\
\text { Diplotaenia, Dorema, Ducrosia, Echinophora, Elaeosticta, } \\
\text { Eleutherospermum, Eremodaucus, Ergocarpon, Eriocycla, } \\
\text { Eryngium, Falcaria, Ferula (=Schumannia), Ferulago, } \\
\text { Foeniculum, Froriepia, Fuernrohria, Galagania, } \\
\text { Glaucosciadium, Glochidotheca (=Turgeniopsis), } \\
\text { Gongylosciadium, Grammosciadium, Haussknechtia, } \\
\text { Heptaptera, Hellenocarum (=Muretia), Heracleum, } \\
\text { Hippomarathrum, Hohenackeria, Hyalolaena, Johrenia, } \\
\text { Johreniopsis, Kalakia, Kelussia, Korovinia, } \\
\text { Korshinskia/Korshinskya, Lagoecia, Laser, Laserpitium, } \\
\text { Lecokia, Leutea, Levisticum, Libanotis, Lisaea, Lomatopodium, } \\
\text { Macrosciadium, Malabaila, Mozaffariania, Myrrhoides } \\
\text { (=Physocaulis), Neocryptodiscus, Oenanthe, Oliveria, Opoidia, } \\
\text { Opopanax, Opsicarpium, Orlaya, Ormosciadium, Pastinaca, } \\
\text { Petroedmondia, Petroselinum, Peucedanum, Physospermum, }\end{array}$ \\
\hline
\end{tabular}




\begin{tabular}{|c|c|c|c|}
\hline & & & $\begin{array}{l}\text { Pimpinella, Polylophium, Prangos, Psammogeton, } \\
\text { Pseudopimpinella, Pseudotrachydium, Pycnocycla, } \\
\text { Rhabdosciadium, Rhopalosciadium, Sanicula, Scaligeria, } \\
\text { Scandix, Sclerochorton, Semenovia, Seseli, Sium, Smyrniopsis, } \\
\text { Smyrnium, Stenotaenia, Szovitsia, Tetrataenium, Thecocarpus, } \\
\text { Tordylium, Torilis, Trachydium, Trachyspermum, } \\
\text { Trigonosciadium, Trinia, Turgenia, Zeravschania, Zosima }\end{array}$ \\
\hline 10 & $\begin{array}{l}\text { Apocynaceae }^{73,103,} \\
28, \underline{41} \\
\text { (incl. } \\
\text { Asclepiadaceae) } \\
\text { [Gentianales] }\end{array}$ & $\begin{array}{l}\text { khaer.zahre.iyan } \\
\text { (خرزهرايان) }\end{array}$ & 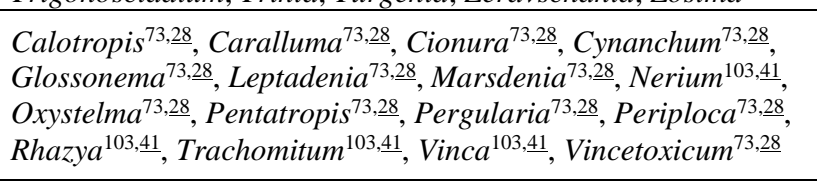 \\
\hline 11 & $\begin{array}{l}\text { Apodanthaceae*136 } \\
\text { [Cucurbitales] }\end{array}$ & $\begin{array}{l}\text { khun.fam.iyan } \\
\text { (خونفاميان) }\end{array}$ & Pilostyles \\
\hline 12 & $\begin{array}{l}\text { Aquifoliaceae }{ }^{25} \\
\text { [Aquifoliales] }\end{array}$ & $\begin{array}{l}\text { khas.iyan } \\
\text { (خاسيان) }\end{array}$ & Ilex \\
\hline 13 & $\begin{array}{l}\text { Araceae }^{3,119, \underline{2}} \\
\text { (incl. Lemnaceae) } \\
\text { [Alismatales] }\end{array}$ & $\begin{array}{l}\text { sheypur.iyan } \\
\text { (شييوريان) }\end{array}$ & $\begin{array}{l}\text { Arum }^{3,2}, \text { Biarum }^{3,2}, \text { Eminium }^{3,2}, \text { Lemna }^{119}, \text { Spirodela }^{119} \text {, } \\
\text { Wolffiall }^{119}\end{array}$ \\
\hline 14 & $\begin{array}{l}\text { Araliaceae }^{102,}, 162, \underline{54} \\
\text { [Apiales] }\end{array}$ & $\begin{array}{l}\text { aesharghe.iyan } \\
\text { (عشقهايان) }\end{array}$ & Hedera ${ }^{102}$, Hydrocotyle $e^{162, \underline{54}}$ \\
\hline 15 & $\begin{array}{l}\text { Aristolochiaceae }{ }^{26,} \\
\underline{29} \\
{[\text { Piperales] }}\end{array}$ & $\begin{array}{l}\text { zaravand.iyan } \\
\text { (زراونديان) }\end{array}$ & Aristolochia \\
\hline 16 & $\begin{array}{l}\text { Asparagaceae } \\
\text { [Asparagales] }\end{array}$ & $\begin{array}{l}\text { marchube.iyan } \\
\text { (مارجوبهايان) }\end{array}$ & $\begin{array}{l}\text { Alrawia, Asparagus, Bellevalia, Danae, Dipcadi, } \\
\text { Hyacinthella,Hyacinthus, Leopoldia, Muscari, Polygonatum, } \\
\text { Puschkinia, Ruscus, Scilla, Urginea }\end{array}$ \\
\hline 17 & $\begin{array}{l}\text { Asphodelaceae } * 151, \\
165 \\
{[\text { Asparagales] }}\end{array}$ & $\begin{array}{l}\text { sirish.iyan } \\
\text { (سريشيان) }\end{array}$ & Asphodeline, Asphodelus, Eremurus \\
\hline 18 & $\begin{array}{l}\text { Asteraceae } e^{90,122,139 a,} \\
\text { 139b, 145, 154, 158, 164, } \underline{59,} \\
\text { 77, (5), (6), (12) } \\
\text { [Asterales] }\end{array}$ & $\begin{array}{l}\text { kasn.iyan } \\
\text { (كاسنيان) }\end{array}$ & 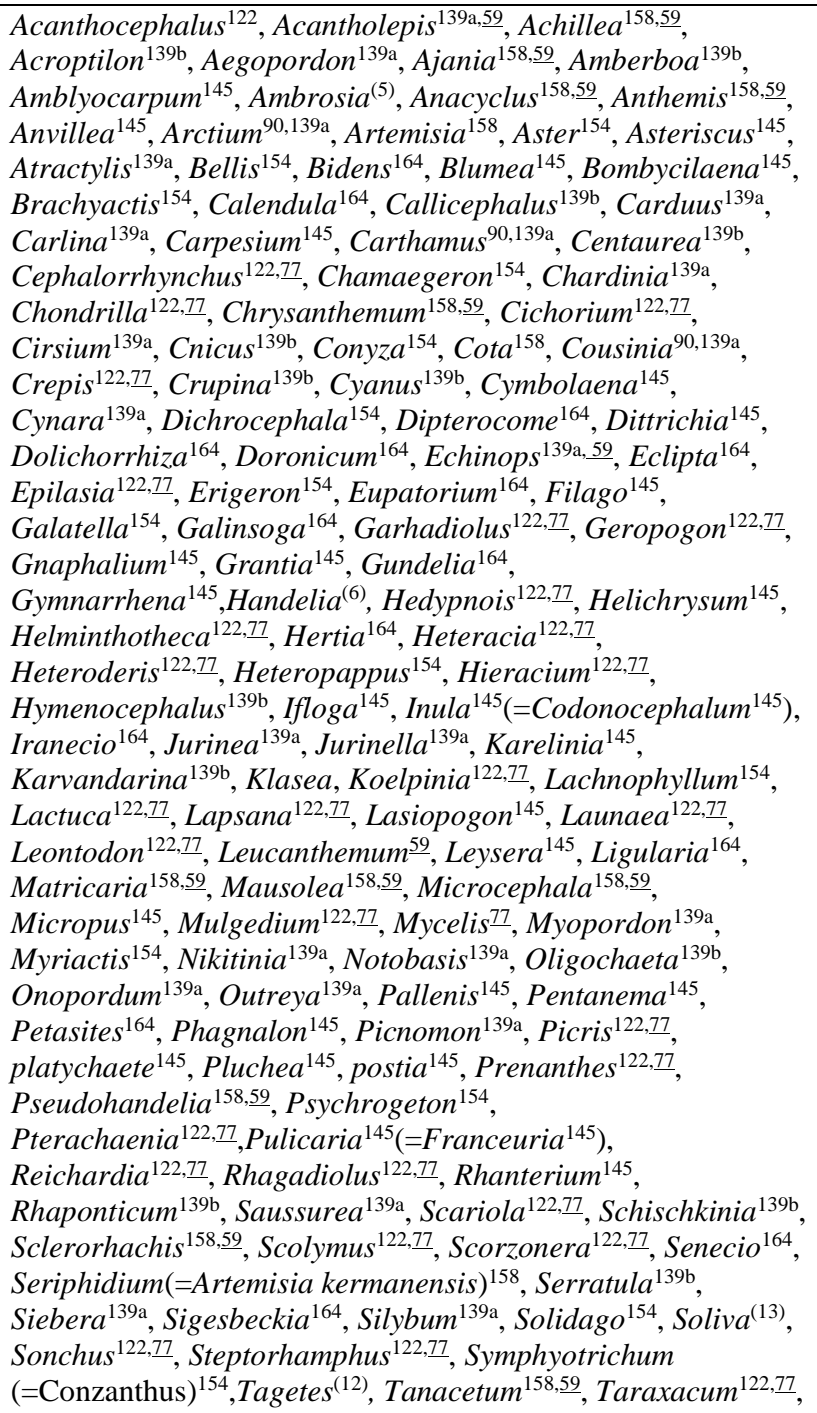 \\
\hline
\end{tabular}




\begin{tabular}{|c|c|c|c|}
\hline & & & $\begin{array}{l}\text { Thevenotia }{ }^{139 a}, \text { Tragopogon }^{122,77}, \text { Tricholepis }^{139 b} \\
\text { Tripleurospermum }^{158,59}, \text { Tussilago }^{164}, \text { Urospermum }^{122,77}, \\
\text { Varthemia }^{145}, \text { Volutaria }^{139 \mathrm{~b}}, \text { Willemetia }^{122,77}, \text { Xanthium }^{164} \text {, } \\
\text { Xeranthemum }^{139 \mathrm{a}}, \text { Zoegea }^{139 \mathrm{~b}}\end{array}$ \\
\hline 19 & $\begin{array}{l}\text { Balsaminaceae } \\
\text { [Ericales] }\end{array}$ & $\begin{array}{l}\text { gole.bisabr.iyan } \\
\text { (كل بى صبريان) }\end{array}$ & Impatiens \\
\hline 20 & $\begin{array}{l}\text { Berberidaceae }^{101,111,} \\
\text { 56, } 64 \text { (incl. } \\
\text { Podophyllaceae) } \\
\text { [Ranunculales] }\end{array}$ & $\begin{array}{l}\text { zereshk.iyan } \\
\text { (زرشكيان) }\end{array}$ & Berberis $^{111, \underline{64}}$, Bongardia $^{101, \underline{56}}$, Epimedium $^{101, \underline{56}}$, Leontice $^{101, \underline{56}}$ \\
\hline 21 & $\begin{array}{l}\text { Betulaceae }^{96,97, \underline{84}} \\
\text { (incl. Corylaceae) } \\
\text { [Fagales] }\end{array}$ & $\begin{array}{l}\text { tuska.'iyan } \\
\text { (توسكاييان) }\end{array}$ & 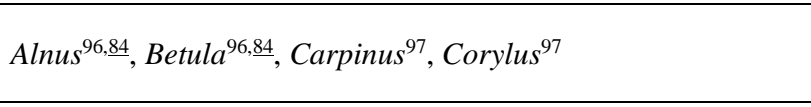 \\
\hline 22 & $\begin{array}{l}\text { Biebersteiniaceae } * 69 \\
, \underline{62} \\
{[\text { Sapindales }]}\end{array}$ & $\begin{array}{l}\text { adamak.iyan } \\
\text { (آدمكيان) }\end{array}$ & Biebersteinia \\
\hline 23 & $\begin{array}{l}\text { Bignoniaceae }^{44} \\
\text { [Lamiales] }\end{array}$ & $\begin{array}{l}\text { pich.onar.iyan } \\
\text { (ييجاناريان) }\end{array}$ & Tecomella \\
\hline 24 & $\begin{array}{l}\text { Boraginaceae }^{48,}, \underline{39}, \\
\text { (11) } \\
{[\text { Boraginales }]}\end{array}$ & $\begin{array}{l}\text { gav.zaban.iyan } \\
\text { (كاوزبانيان) }\end{array}$ & 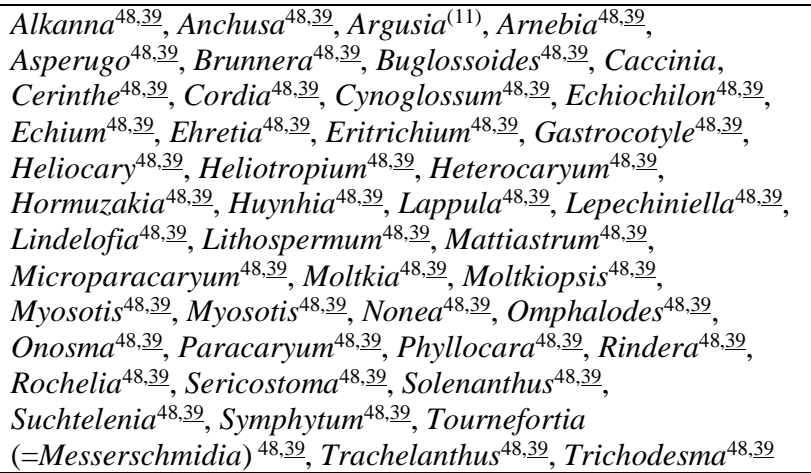 \\
\hline 25 & $\begin{array}{l}\text { Brassicaceae }^{57} \\
\text { [Brassicales] }\end{array}$ & $\begin{array}{l}\text { kaelam.iyan } \\
\text { (كلميان) }\end{array}$ & $\begin{array}{l}\text { Acanthocardamun, Aethionema, Alliaria, Alyssopsis, Alyssum, } \\
\text { Anastatica, Anchonium, Arabidopsis, Arabis, Asperuginoides } \\
\text { (=Buchingera), Aubrieta, Biscutella, Boreava, Brassica, } \\
\text { Brossardia, Bunias, Cakile, Calepina, Camelina, Capsella, } \\
\text { Cardamine, Carrichtera, Chalcanthus, Chorispora, } \\
\text { Cithareloma, Clastopus, Clausia, Clypeola, Coluteocarpus, } \\
\text { Conringia, Coronopus, Crambe, Cryptospora, Cymatocarpus, } \\
\text { Descurainia, Diceratella, Didymophysa, Dielsiocharis, } \\
\text { Diplotaxis, Diptychocarpus, Draba, Drabopsis, Elburzia, } \\
\text { Eremobium, Erophila, Eruca, Erucaria, Erysimum, Euclidium, } \\
\text { Farsetia, Fibigia, Fortuynia, Goldbachia, Graellsia, } \\
\text { Heldreichia, Hesperis (=Micrantha), Hirschfeldia, } \\
\text { Hymenolobus, Ianhedgea (=Microsisymbrium), Iberis, Isatis, } \\
\text { Lachnoloma, Lepidium (=Cardaria), Leptaleum, Lobularia, } \\
\text { Malcolmia, Maresia, Matthiola, Moricandia, Moriera, } \\
\text { Myagrum, Nasturtium, Neotorularia, Neslia, Noccaea, } \\
\text { Notoceras, Octoceras, Pachypterygium, Parlatoria, Peltaria, } \\
\text { Peltariopsis, Petrocallis, Physoptychis, Physorrhynchus, } \\
\text { pseudocamelina, Pseudofortuynia, Raphanus, Rapistrum, } \\
\text { Robeschia, Rorippa, Sameraria, Savignya, Schimpera, Sinapis, } \\
\text { Sisymbrium, Spirorhynchus, Sterigmostemum, Straussiella, } \\
\text { Streptoloma, Stroganowia, Tauscheria, Tetracme, Thlaspi, } \\
\text { Torularia, Turritis, Zerdana }\end{array}$ \\
\hline 26 & $\begin{array}{l}\text { Butomaceae }^{79} \\
\text { [Alismatales] }\end{array}$ & $\begin{array}{l}\text { hezar.ne.'iyan } \\
\text { (هزارنىايان) }\end{array}$ & Butomus \\
\hline 27 & $\begin{array}{l}\text { Buxaceae }^{27} \\
{[\text { Buxales] }}\end{array}$ & $\begin{array}{l}\text { shemshad.iyan } \\
\text { (شمشاديان) }\end{array}$ & Buxus \\
\hline 28 & $\begin{array}{l}\text { Campanulaceae } 66, \underline{13} \\
\text { [Asterales] }\end{array}$ & $\begin{array}{l}\text { gol.estekan.iyan } \\
\text { (كل استكانيان) }\end{array}$ & $\begin{array}{l}\text { Asyneuma, Campanula, Legousia, Michauxia (=Mindium), } \\
\text { Symphyandra, Zeugandra }\end{array}$ \\
\hline 29 & $\begin{array}{l}\text { Cannabaceae }^{138,142,} \\
\underline{4} \\
\text { [Rosales] }\end{array}$ & $\begin{array}{l}\text { shah.dane.'iyan } \\
\text { (شاهدانهايان) }\end{array}$ & Cannabis $^{138}$, Celtis $^{142,4}$, Humulus ${ }^{138}$ \\
\hline 30 & $\begin{array}{l}\text { Capparaceae }^{68,}, \underline{30} \\
\text { [Brassicales] }\end{array}$ & $\begin{array}{l}\text { kabar.iyan } \\
\text { (كبريان) }\end{array}$ & Cadaba $^{68, \underline{30}}$, Capparis $^{68, \underline{30}}$, Maerua $^{68, \underline{30}}$ \\
\hline 31 & $\begin{array}{l}\text { Caprifoliaceae }^{10,62,} \\
\text { 168, } \underline{8}, \underline{37}, \underline{63} \text { (incl. }\end{array}$ & $\begin{array}{l}\text { aght.iyan } \\
\text { (آطيان) }\end{array}$ & 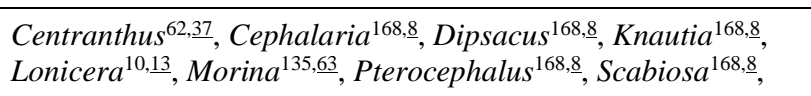 \\
\hline
\end{tabular}




\begin{tabular}{|c|c|c|c|}
\hline & $\begin{array}{l}\text { Dipsacaceae, } \\
\text { Morinnaceae \& } \\
\text { Valerianaceae) } \\
\text { [Dipsacales] }\end{array}$ & & Scabiosiopsis $^{168,8}$, Valeriana $^{62,37}$, Valerianella $^{62,37}$ \\
\hline 32 & $\begin{array}{l}\text { Caryophyllaceae }{ }^{144,} \\
\text { 163, } \underline{65} \\
\text { [Caryophyllales] }\end{array}$ & $\begin{array}{l}\text { mikhaek.iyan } \\
\text { (ميخكيان) }\end{array}$ & 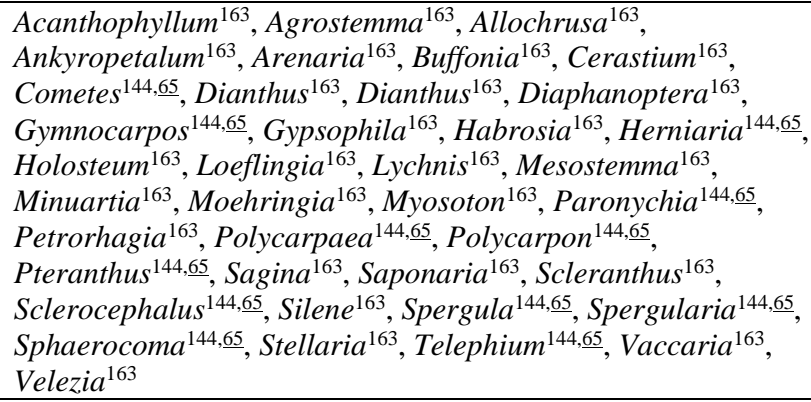 \\
\hline 33 & $\begin{array}{l}\text { Celastraceae }{ }^{20,64} \\
\text { (incl. Parnassiaceae) } \\
\text { [Celastrales] }\end{array}$ & $\begin{array}{l}\text { gushvarak.iyan } \\
\text { (كوشوار كيان) }\end{array}$ & Euonymus $^{64}$, Gymnoporia $^{64}$, Parnassia $^{20}$ \\
\hline 34 & $\begin{array}{l}\text { Cistaceae }^{46,}, \underline{69} \\
\text { [Malvales] }\end{array}$ & $\begin{array}{l}\text { gol.aftab.iyan } \\
\text { (كل آفتابيان) }\end{array}$ & Cistus $^{46, \underline{69}}$, Fumana $^{46,69}$, Helianthemum $^{46,69}$ \\
\hline 35 & $\begin{array}{l}\text { Cleomaceae } * 68, \underline{30} \\
\text { [Brassicales] }\end{array}$ & $\begin{array}{l}\text { alaef.mar.iyan } \\
\text { (علفماريان) }\end{array}$ & Cleome $\left(=\right.$ Buhsea $^{68, \underline{30}}$,Dipterygium $^{68, \underline{30}}$ \\
\hline 36 & $\begin{array}{l}\text { Colchicaceae }{ }^{* 165,}, 170 \\
\text { [Liliales] }\end{array}$ & $\begin{array}{l}\text { gol.hassrat.iyan } \\
\text { (كلحسرتيان) }\end{array}$ & Colchicum \\
\hline 37 & $\begin{array}{l}\text { Convolvolaceae } e^{1,8, \underline{40}} \\
\text { (incl. Cuscutaceae) } \\
\text { [Solanales] }\end{array}$ & $\begin{array}{l}\text { pichak.iyan } \\
\text { (يبحكيان) }\end{array}$ & $\begin{array}{l}\text { Calystegia }^{1, \underline{40}}, \text { Convolvulus }^{1,40}, \text { Cressa }^{1,40}, \text { Cuscuta }^{8} \text {, } \\
\text { Ipomoea }^{1, \underline{40}}\end{array}$ \\
\hline 38 & $\begin{array}{l}\text { Cornaceae }^{54,} \underline{83} \\
\text { [Cornales] }\end{array}$ & $\begin{array}{l}\text { zoghal.'aekhte.'iyan } \\
\text { (ذغال|ختهايان) }\end{array}$ & Cornus \\
\hline 39 & $\begin{array}{l}\text { Crassulaceae }^{72,}, \underline{32} \\
\text { [Saxifragales] }\end{array}$ & $\begin{array}{l}\text { golnaz.iyan } \\
\text { (كل نازيان }\end{array}$ & $\begin{array}{l}\text { Crassula, Pseudosedum, Rosularia, Sedum, Sempervivum, } \\
\text { Umbilicus }\end{array}$ \\
\hline 40 & $\begin{array}{l}\text { Cucurbitaceae } \\
\text { [Cucurbitales] }\end{array}$ & $\begin{array}{l}\text { kaedu.'iyan } \\
\text { (كدوئيان) }\end{array}$ & Bryonia, Citrullus, Corallocarpus, Cucumis, Ecballium \\
\hline 41 & $\begin{array}{l}\text { Cymodoceaceae*85 } \\
\text { [Alismatales] }\end{array}$ & without Persian name & Halodule, Thalassodendron \\
\hline 42 & $\begin{array}{l}\text { Cynomoriaceae }^{129} \\
{[\text { Saxifragales] }}\end{array}$ & $\begin{array}{l}\text { khunin.gorz.iyan } \\
\text { (خونين خرزيان) }\end{array}$ & Cynomorium \\
\hline 43 & $\begin{array}{l}\text { Cyperaceae }{ }^{173,}, \underline{11} \\
\text { [Poales] }\end{array}$ & $\begin{array}{l}\text { jagaen.iyan } \\
\text { (جگنيان) }\end{array}$ & $\begin{array}{l}\text { Blysmus, Bolboschoenus, Carex, Cladium, Cyperus, } \\
\text { Eleocharis, Eriophorum (=Erioscirpus), Fimbristylis, Fuirena, } \\
\text { Isolepis, Kobresia, Pycreus, Schoenoplectus, Schoenus, } \\
\text { Scirpoides, Trichophorum }\end{array}$ \\
\hline 44 & $\begin{array}{l}\text { Ebenaceae }^{30} \\
\text { [Ericales] }\end{array}$ & $\begin{array}{l}\text { khormalu.'iyan } \\
\text { (خرمالوئيان) }\end{array}$ & 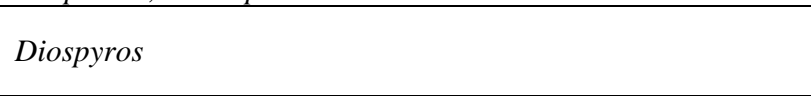 \\
\hline 45 & $\begin{array}{l}\text { Elaeagnaceae }^{55} \\
\text { [Rosales] }\end{array}$ & $\begin{array}{l}\text { senjed.iyan } \\
\text { (سنجديان) }\end{array}$ & Elaeagnus, Hippophae \\
\hline 46 & $\begin{array}{l}\text { Ericaceae }^{11,93,94} \\
\text { (incl. Monotropaceae } \\
\text { \& Pyrolaceae) } \\
\text { [Ericales] }\end{array}$ & $\begin{array}{l}\text { khaelang.iyan } \\
\text { (خلنخيان) }\end{array}$ & Monotropa $^{94}$, Orthilia $^{93}$, Pyrola $^{93}$, Vaccinium $^{11}$ \\
\hline 47 & $\begin{array}{l}\text { Euphorbiaceae }^{6} \\
\text { [Malpighiales] }\end{array}$ & $\begin{array}{l}\text { farfiyun.iyan } \\
\text { (فرفيونيان) }\end{array}$ & Chrozophora, Euphorbia, Mercurialis, Ricinus \\
\hline 48 & $\begin{array}{l}\text { Fabaceae } 140,157,160 \\
161,174,175,177,178,179 \\
\underline{18}, \underline{33}, \underline{43}, \underline{45}, \underline{85} \\
{[\text { Fabales }]}\end{array}$ & $\begin{array}{l}\text { baghela.'iyan } \\
\text { (باقلائيان) }\end{array}$ & 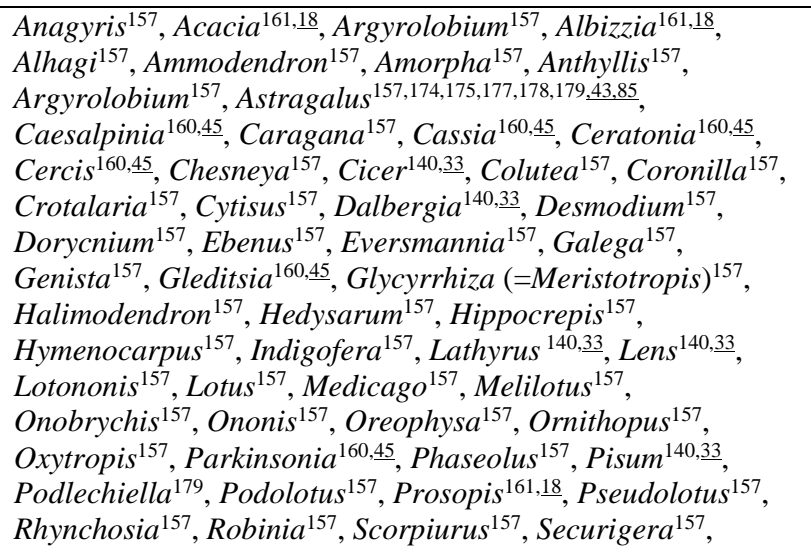 \\
\hline
\end{tabular}




\begin{tabular}{|c|c|c|c|}
\hline & & & $\begin{array}{l}\text { Senna }{ }^{160}, \text { Sesbania }{ }^{157}, \text { Smirnowia }{ }^{157}, \text { Sophora } \\
\left(={\text { Ammothamnus })^{157}, \text { Spartium }^{157}, \text { Sphaerophysa }}^{157},\right. \\
\text { Taverniera }^{157}, \text { Tephrosia }^{157}, \text { Trifolium }^{157}, \text { Trigonella }^{157}, \text { Vicia } \\
\left(=\text { Faba }^{140, \underline{3}}, \text { Vigna }^{157}\right.\end{array}$ \\
\hline 49 & $\begin{array}{l}\text { Fagaceae }^{77} \\
\text { [Fabales] }\end{array}$ & $\begin{array}{l}\text { rash.iyan } \\
\text { (راشيان) }\end{array}$ & Fagus, Quercus \\
\hline 50 & $\begin{array}{l}\text { Frankeniaceae }{ }^{99,} \underline{11} \\
\text { [Caryophyllales] }\end{array}$ & $\begin{array}{l}\text { shaebnam.iyan } \\
\text { (شبنميان) }\end{array}$ & Frankenia $(=$ Hypericopsis $)$ \\
\hline 51 & $\begin{array}{l}\text { Gentianaceae }{ }^{41,} \underline{16} \\
\text { [Gentianales] }\end{array}$ & $\begin{array}{l}\text { gol.sepas.iyan } \\
\text { (كل سياسيان) }\end{array}$ & Centaurium, Gentiana, Gentianella, Lomatogonium, Swertia \\
\hline 52 & $\begin{array}{l}\text { Geraniaceae }^{69,} \underline{62} \\
\text { [Geraniales] }\end{array}$ & $\begin{array}{l}\frac{\text { sha'mdan.iyan }}{\text { (شمعدانيان) }} \\
\text { (شع) }\end{array}$ & Erodium, Geranium, Monsonia, Pelargonium \\
\hline 53 & $\begin{array}{l}\text { Gisekiaceae* } * 114, \underline{53} \\
\text { [Caryophyllales] }\end{array}$ & without Persian name & Gisekia \\
\hline 54 & $\begin{array}{l}\text { Grossulariaceae }^{47,} \underline{23} \\
\text { [Saxifragales] }\end{array}$ & $\begin{array}{l}\text { angur.farceng.iyan } \\
\text { (انغورفرنخيان) }\end{array}$ & Ribes \\
\hline 55 & $\begin{array}{l}\text { Haloragaceae } \\
\text { [Saxifragales] }\end{array}$ & $\begin{array}{l}\text { hezar.barg.iyan } \\
\text { (هزاربر كيان) }\end{array}$ & Myriophyllum \\
\hline 56 & $\begin{array}{l}\text { Hamamelidaceae } \\
\text { [Saxifragales] }\end{array}$ & $\begin{array}{l}\text { anjil.iyan } \\
\text { (انجيليان) }\end{array}$ & Parrotia \\
\hline 57 & $\begin{array}{l}\text { Hydrocharitaceae }^{80,} \\
86 \\
\text { (incl. Najadaceae) } \\
\text { [Alismatales] }\end{array}$ & $\begin{array}{l}\text { takht.ghurbaghe.iyan } \\
\text { (تخت قورباغهايان) }\end{array}$ & $\begin{array}{l}\text { Blyxa }^{80}, \text { Halophila }^{80}, \text { Hydrilla } \\
\text { Vallisneria }\end{array}$ \\
\hline 58 & $\begin{array}{l}\text { Hypericaceae } * 49, \underline{27} \\
\text { [Malpighiales] }\end{array}$ & $\begin{array}{l}\text { golra.'iyan } \\
\text { (كلراعيان) }\end{array}$ & Hypericum \\
\hline 59 & $\begin{array}{l}\text { Iridaceae }^{112,} \underline{31,(12)} \\
\text { [Asparagales] }\end{array}$ & $\begin{array}{l}\text { zanbagh.iyan } \\
\text { (زنبقيان) }\end{array}$ & $\begin{array}{l}\text { Crocus }^{112, \underline{1}}, \text { Gladiolus }^{112,31}, \text { Moraea }\left(=\text { Gynandriris }^{112,31} \text {, }\right. \\
\text { Iris }^{112, \underline{31}}, \text { Sisyrinchium }^{(12)}\end{array}$ \\
\hline 60 & $\begin{array}{l}\text { Ixioliriaceae } * 67, \underline{46} \\
\text { [Asparagales] }\end{array}$ & $\begin{array}{l}\text { khiarak.iyan } \\
\text { (خيار كيان) }\end{array}$ & Ixiolirion \\
\hline 61 & $\begin{array}{l}\text { Juglandaceae } \\
\text { [Fagales] }\end{array}$ & $\begin{array}{l}\text { gerdu.'iyan } \\
\text { (كردوئيان) }\end{array}$ & Juglans, Pterocarya \\
\hline 62 & $\begin{array}{l}\text { Juncaceae }^{75, \underline{10}} \\
\text { [Poales] }\end{array}$ & $\begin{array}{l}\text { sazu.'iyan } \\
\text { (سازوئيان) }\end{array}$ & Juncus, Luzula \\
\hline 63 & $\begin{array}{l}\text { Lamiaceae } \\
\text { [Lamiales] }\end{array}$ & $\begin{array}{l}\text { na'na.'iyan } \\
\text { (نعنائيان) }\end{array}$ & 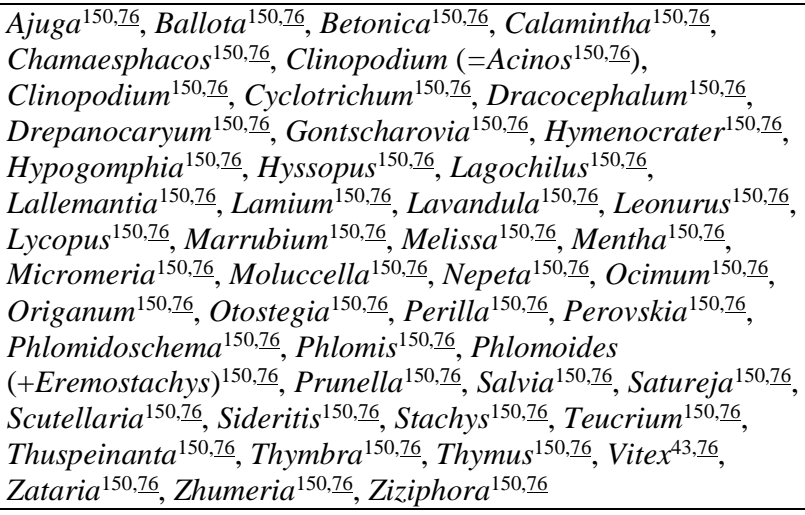 \\
\hline 64 & $\begin{array}{l}\text { Lentibulariaceae }{ }^{58} \\
\text { [Lamiales] }\end{array}$ & $\begin{array}{l}\text { alaef.'cenban.iyan } \\
\text { (علفانبانيان) }\end{array}$ & Utricularia \\
\hline 65 & $\begin{array}{l}\text { Liliaceae }^{165} \\
\text { [Liliales] }\end{array}$ & $\begin{array}{l}\text { susaen.'iyan } \\
\text { (سوسنيان) }\end{array}$ & $\begin{array}{l}\text { Erythronium, Fritillaria, Gagea, Lilium, Notholirion, } \\
\text { Ornithogalum, Tulipa }\end{array}$ \\
\hline 66 & $\begin{array}{l}\text { Limeaceae } * 114, \underline{53} \\
\text { [Caryophyllales] }\end{array}$ & without Persian name & Limeum \\
\hline 67 & $\begin{array}{l}\text { Linaceae }^{106,}, \underline{34} \\
\text { [Malpighiales] }\end{array}$ & $\begin{array}{l}\text { katan.iyan } \\
\text { (كتانيان) }\end{array}$ & Linum \\
\hline 68 & $\begin{array}{l}\text { Linderniaceae* } * 147, \underline{68} \\
\text { [Lamiales] }\end{array}$ & without Persian name & Lindernia \\
\hline 69 & $\begin{array}{l}\text { Lophiocarpaceae } * 11 \\
4 \\
\text { [Caryophyllales] }\end{array}$ & without Persian name & Corbichonia \\
\hline 70 & $\begin{array}{l}\text { Loranthaceae }^{116,} \underline{72} \\
\text { [Santalales] }\end{array}$ & $\begin{array}{l}\text { mukhore.'iyan } \\
\text { (موخورهايان) }\end{array}$ & Loranthus $^{116, \underline{72}}$ \\
\hline
\end{tabular}




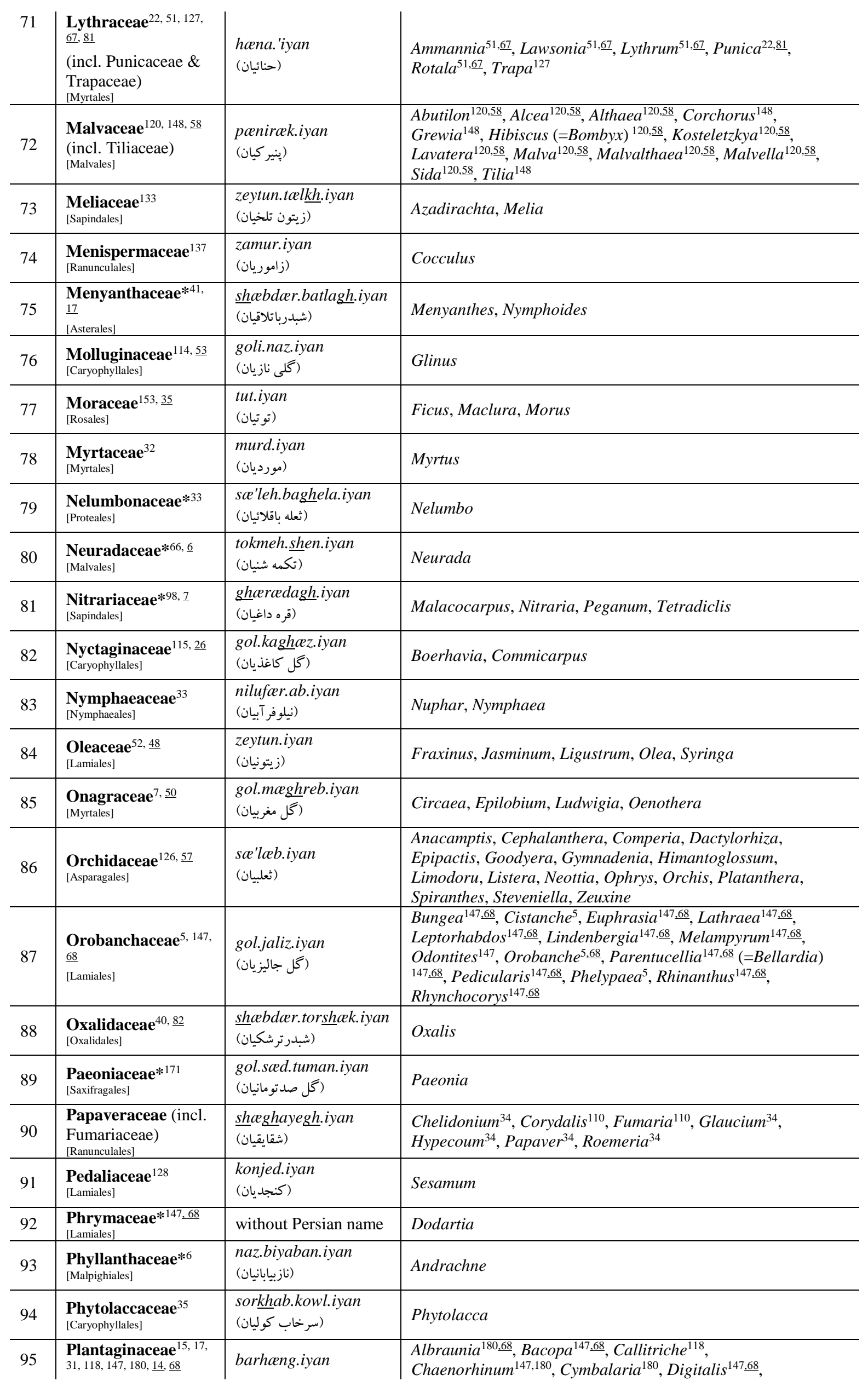




\begin{tabular}{|c|c|c|c|}
\hline & $\begin{array}{l}\text { (incl. Callitrichaceae } \\
\text { Link, Globulariaceae } \\
\text { DC. \& } \\
\text { Hippuridaceae Link.) } \\
\text { [Lamiales] }\end{array}$ & 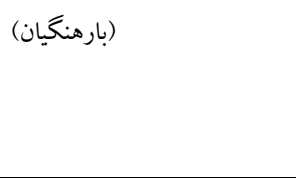 & $\begin{array}{l}\text { Globularia }^{17}, \text { Gratiola }^{147,68}, \text { Hippuris }^{31}, \text { Holzneria }^{180,68}, \\
\text { Kickxia }^{147,180,68}, \text { Lagotis }^{147,68}, \text { Limosella }^{147,68}, \text { Linaria }^{147,180,68}, \\
\text { Misopates }^{147,180,68}, \text { Nanorrhinum }^{180,68}, \text { Plantago }^{15, \underline{14}}, \\
\text { Schweinfurthia }^{147,180,68}, \text { Veronica }^{147, \underline{68}}\end{array}$ \\
\hline 96 & $\begin{array}{l}\text { Platanaceae }^{21} \\
\text { [Proteales] }\end{array}$ & $\begin{array}{l}\text { chenar.iyan } \\
(\text { ) }\end{array}$ & Platanus \\
\hline 97 & $\begin{array}{l}\text { Plumbaginaceae }^{108,} \\
\underline{51},(11) \\
\text { [Caryophyllales] }\end{array}$ & $\begin{array}{l}\text { kolah.mir.haesan.iyan } \\
\text { (كلاه ميرحسنيان) }\end{array}$ & $\begin{array}{l}\text { Acantholimon }{ }^{108, \underline{51}}, \text { Cephalorhizum } \\
\text { Plumbago }^{108, \underline{51}}, \underline{51} \text {, }_{\text {Popovimonium }} \text { Limon }^{108,51}, \text { Psylliostachys }^{108,51}\end{array}$ \\
\hline 98 & $\begin{array}{l}\text { Poaceae }^{70,(1),(2),(3),} \\
\text { (4), (7), (9), (10), (11) } \\
\text { [Poales] }\end{array}$ & $\begin{array}{l}\text { gandom.iyan } \\
\text { (كندميان) }\end{array}$ & 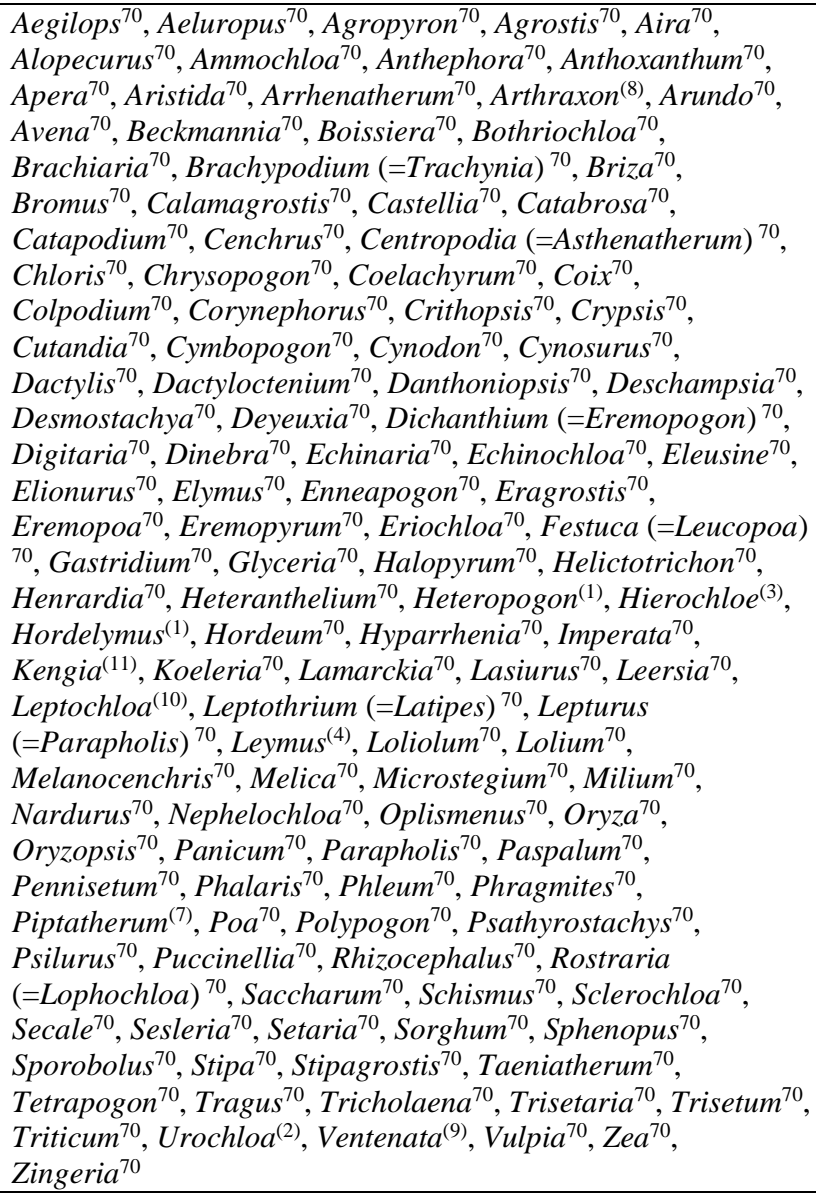 \\
\hline 99 & $\begin{array}{l}\text { Polygalaceae }{ }^{124,} \underline{49} \\
\text { [Fabales] }\end{array}$ & $\begin{array}{l}\text { shiravar.iyan } \\
\text { (شير آوريان) }\end{array}$ & Polygala \\
\hline 100 & $\begin{array}{l}\text { Polygonaceae } \\
\text { [Caryophyllales] }\end{array}$ & $\begin{array}{l}\text { aelaef.haeft.band.iyan } \\
\text { (علف هفت بنديان) }\end{array}$ & $\begin{array}{l}\text { Atraphaxis }^{56}, \text { Calligonum }^{56}, \text { Emex }^{56}, \text { Oxyria }^{56}, \text { Persicaria }^{(11)} \text {, } \\
\text { Polygonum }^{56}, \text { Pteropyrum }^{56}, \text { Rheum }^{56}, \text { Rumex }^{56}\end{array}$ \\
\hline 101 & $\begin{array}{l}\text { Pontederiaceae }{ }^{167} \\
\text { [Commelinales] }\end{array}$ & $\begin{array}{l}\text { ghaelaf.iyan } \\
\text { (غلافيان) }\end{array}$ & Monochoria \\
\hline 102 & $\begin{array}{l}\text { Portulacaceae }^{117} \\
\text { [Caryophyllales] }\end{array}$ & 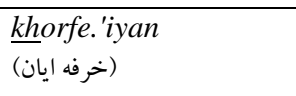 & Portulaca \\
\hline 103 & $\begin{array}{l}\text { Potamogetonaceae }^{83} \\
, 85 \\
{[\text { Alismatales] }}\end{array}$ & $\begin{array}{l}\text { gushab.iyan } \\
\text { (كوشابيان) }\end{array}$ & Althenia $^{85}$, Groenlandia $^{83}$, Potamogeton $^{83}$, Zannichellia $^{85}$ \\
\hline 104 & $\begin{array}{l}\text { Primulaceae }^{9,}, \underline{25} \\
\text { [Ericales] }\end{array}$ & $\begin{array}{l}\text { pamchal.iyan } \\
\text { (يامجاليان) }\end{array}$ & $\begin{array}{l}\text { Anagallis, Androsace, Cortusa, Cyclamen, Dionysia, Glaux, } \\
\text { Lysimachia, Primula, Samolus }\end{array}$ \\
\hline 105 & $\begin{array}{l}\text { Ranunculaceae }{ }^{171} \\
\text { [Ranunculales] }\end{array}$ & $\begin{array}{l}\text { alale.'iyan } \\
\text { (آلاله ايان) }\end{array}$ & $\begin{array}{l}\text { Aconitum, Actaea, Adonis, Anemone, Aquilegia, Batrachium, } \\
\text { Caltha, Ceratocephala, Clematis, Consolida, Delphinium, } \\
\text { Eranthis, Ficaria, Halerpestes, Myosurus, Nigella, } \\
\text { Paraquilegia, Pulsatilla, Ranunculus, Thalictrum, Trollius }\end{array}$ \\
\hline 106 & $\begin{array}{l}\text { Resedaceae }^{149} \\
\text { [Brassicales] }\end{array}$ & $\begin{array}{l}\text { esparak.iyan } \\
\text { (اسير كيان) }\end{array}$ & Ochradenus, Oligomeris, Reseda \\
\hline 107 & $\begin{array}{l}\text { Rhamnaceae }^{125,} \underline{55} \\
\text { [Rosales] }\end{array}$ & $\begin{array}{l}\text { annab.iyan } \\
\text { (عنابيان) }\end{array}$ & Frangula, Paliurus, Rhamnus, Sageretia, Ziziphus \\
\hline 108 & $\begin{array}{l}\text { Rhizophoraceae }{ }^{166}, \\
\underline{80}\end{array}$ & $\begin{array}{l}\text { chandal.iyan } \\
\text { (جندليان) }\end{array}$ & Rhizophora \\
\hline
\end{tabular}




\begin{tabular}{|c|c|c|c|}
\hline & [Malpighiales] & & \\
\hline 109 & $\begin{array}{l}\text { Rosaceae }^{66,152,}, \underline{6} \\
\text { [Rosales] }\end{array}$ & $\begin{array}{l}\text { gol.sorkh.iyan } \\
\text { (كلسرخيان) }\end{array}$ & 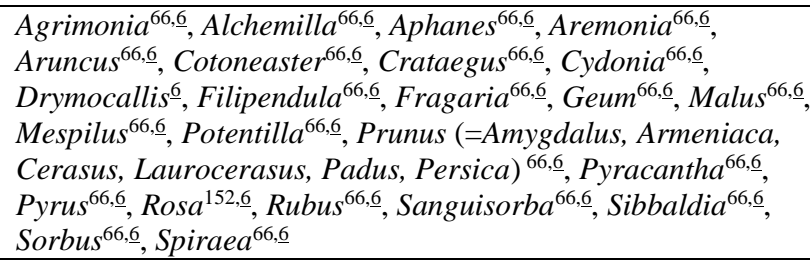 \\
\hline 110 & $\begin{array}{l}\text { Rubiaceae }^{39,176} \\
\text { (incl. Theligonaceae) } \\
\text { [Gentianales] }\end{array}$ & $\begin{array}{l}\text { ronas.iyan } \\
\text { (روناسيان) }\end{array}$ & $\begin{array}{l}\text { Aitchisonia }^{176}, \text { Asperula }^{176}, \text { Callipeltis }^{176}, \text { Crucianella }^{176}, \\
\text { Gaillonia }^{176}, \text { Galium }^{176}, \text { Oldenlandia }^{176}, \text { Putoria }^{176}, \text { Randia }^{176}, \\
\text { Rubia }^{176}, \text { Sherardia }^{176}, \text { Theligonum }^{39}, \text { Valantia }^{176}\end{array}$ \\
\hline 111 & $\begin{array}{l}\text { Rutaceae }^{36,}, \underline{60} \\
\text { [Sapindales] }\end{array}$ & $\begin{array}{l}\text { sodab.iyan } \\
\text { (سدابيان) }\end{array}$ & Dictamnus, Haplophyllum, Ruta \\
\hline 112 & $\begin{array}{l}\text { Salicaceae } 65,74 \\
\text { [Malpighiales] }\end{array}$ & $\begin{array}{l}\text { bid.iyan } \\
\text { (بيديان) }\end{array}$ & Populus, Salix \\
\hline 113 & $\begin{array}{l}\text { Salvadoraceae }{ }^{37,} \underline{79} \\
\text { [Brassicales] }\end{array}$ & $\begin{array}{l}\text { mes.vak.iyan } \\
\text { (مسواكيان) }\end{array}$ & Salvadora \\
\hline 114 & $\begin{array}{l}\text { Santalaceae }{ }^{116,155, \underline{73}} \\
\text { (incl. Viscaceae) } \\
\text { [Santalales] }\end{array}$ & $\begin{array}{l}\text { sandael.iyan } \\
\text { (صندليان) }\end{array}$ & Arceuthobium $^{116, \underline{73}}$,Osyris $^{155}$, Thesium $^{155}$, Viscum ${ }^{116, \underline{73}}$ \\
\hline 115 & $\begin{array}{l}\text { Sapindaceae }{ }^{38,61} \\
\text { (incl. Aceraceae) } \\
\text { [Sapindales] }\end{array}$ & $\begin{array}{l}\text { na.torak.iyan } \\
\text { (ناتر كيان) }\end{array}$ & Acer $^{61}$, Dodonaea $^{38}$, Stocksia $^{38}$ \\
\hline 116 & $\begin{array}{l}\text { Saxifragaceae } \\
\text { [Saxifragales] }\end{array}$ & $\begin{array}{l}\text { kharashekan.iyan } \\
\text { (خاراشكنيان) }\end{array}$ & Saxifraga \\
\hline 117 & $\begin{array}{l}\text { Scrophulariaceae }^{147}, \\
\underline{68} \\
{[\text { Lamiales] }}\end{array}$ & $\begin{array}{l}\text { gol.meymun.iyan } \\
\text { (كل ميمونيان) }\end{array}$ & Scrophularia, Verbascum \\
\hline 118 & $\begin{array}{l}\text { Simaroubaceae } \\
\text { [Sapindales] }\end{array}$ & $\begin{array}{l}\text { ar.ar.iyan } \\
\text { (عرعريان) }\end{array}$ & Ailanthus \\
\hline 19 & $\begin{array}{l}\text { Smilacaceae } \\
\text { [Liliales] }\end{array}$ & $\begin{array}{l}\text { azmaelaek.iyan } \\
\text { (ازملكيان) }\end{array}$ & Smilax \\
\hline 120 & $\begin{array}{l}\text { Solanaceae }{ }^{100,} \underline{24} \\
\text { [Solanales] }\end{array}$ & $\begin{array}{l}\text { baden.jan.iyan } \\
\text { (بادنجانيان) }\end{array}$ & $\begin{array}{l}\text { Atropa, Datura, Hyoscyamus, Lycium, Physalis, Physochlaina, } \\
\text { Solanum, Withania }\end{array}$ \\
\hline 121 & $\begin{array}{l}\text { Sphenocleaceae }{ }^{88} \\
\text { [Solanales] }\end{array}$ & $\begin{array}{l}\text { varras.ab.iyan } \\
\text { (ورث آبيان) }\end{array}$ & Sphenoclea \\
\hline 122 & $\begin{array}{l}\text { Tamaricaceae } \\
\text { [Caryophyllales] }\end{array}$ & $\begin{array}{l}\text { gaz.iyan } \\
\text { (گزيان) }\end{array}$ & Myricaria, Reaumuria, Tamarix \\
\hline 123 & $\begin{array}{l}\text { Thymelaeaceae }{ }^{95,} \underline{15} \\
\text { [Malvales] }\end{array}$ & $\begin{array}{l}\text { ma.zariyun.iyan } \\
\text { (مازريونيان) }\end{array}$ & $\begin{array}{l}\text { Taxus, Daphne, Dendrostellera, Diarthron, Stelleropsis, } \\
\text { Thymelaea }\end{array}$ \\
\hline 124 & $\begin{array}{l}\text { Typhaceae } \\
\text { [Poales] }\end{array}$ & $\begin{array}{l}\text { lu'.iyan } \\
\text { (لوئيان) }\end{array}$ & Sparganium $^{59}$, Typha $^{71, \underline{42}}$ \\
\hline 125 & Ulmaceae $^{162, \underline{4}}$ & $\begin{array}{l}\text { nar.vaen.iyan } \\
\text { (نارونيان) }\end{array}$ & Ulmus, Zelkova \\
\hline 126 & $\begin{array}{l}\text { Urticaceae }^{105,} \underline{36} \\
\text { [Rosales] }\end{array}$ & $\begin{array}{l}\text { ga.zane.'iyan } \\
\text { (كزنهايان) }\end{array}$ & Forsskaolea, Parietaria, Urtica \\
\hline 127 & $\begin{array}{l}\text { Vahliaceae }^{23,(14)} \\
\text { [Vahliales] }\end{array}$ & without Persian name & Vahlia \\
\hline 128 & $\begin{array}{l}\text { Verbenaceae }^{43,} \underline{52} \\
\text { [Lamiales] }\end{array}$ & $\begin{array}{l}\text { shah.pasand.iyan } \\
\text { (شاهيسنديان) }\end{array}$ & Phyla, Verbena \\
\hline 129 & $\begin{array}{l}\text { Violaceae }^{169, \underline{5}} \\
\text { [Malpighiales] }\end{array}$ & $\begin{array}{l}\text { baenaefshe.iyan } \\
\text { (بنفشهايان) }\end{array}$ & Viola \\
\hline 130 & $\begin{array}{l}\text { Vitaceae }^{74} \\
\text { [Vitales] }\end{array}$ & $\begin{array}{l}\text { angur.iyan } \\
\text { (انكوريان) }\end{array}$ & Ampelopsis, Vitis \\
\hline 131 & $\begin{array}{l}\text { Zosteraceae }^{81} \\
\text { [Alismatales] }\end{array}$ & $\begin{array}{l}\text { na.var.iyan } \\
\text { (نواريان) }\end{array}$ & Zostera \\
\hline 132 & $\begin{array}{l}\text { Zygophyllaceae } \\
\text { [Zygophyllales] }\end{array}$ & $\begin{array}{l}\text { ghich.iyan } \\
\text { (قيجيان }\end{array}$ & Fagonia, Seetzenia, Tribulus, Zygophyllum \\
\hline
\end{tabular}

${ }^{1}$ Rechinger, 1963; ${ }^{2}$ Riedl, 1963b; ${ }^{3}$ Riedl, 1963a; ${ }^{4}$ Schiman-Czeika, 1964b; ${ }^{5}$ Schiman-Czeika, 1964a; ${ }^{6}$ Rechinger \& SchimanCzeika, 1964; ${ }^{7}$ Raven, 1964; ${ }^{8}$ Yuncker \& Rechinger, 1964; ${ }^{9}$ Wendelbo, 1965c; ${ }^{10}$ Wendelbo, 1965a; ${ }^{11}$ Wendelbo, 1965b; ${ }^{12}$ Riedl, 1965b; ${ }^{13}$ Rechinger \& Schiman-Czeika, 1965; ${ }^{15}$ Patzak \& Rechinger, 1965; ${ }^{16}$ Rechinger, 1966h; ${ }^{17}$ Rechinger, 1966i; ${ }^{18}$ Rechinger, 1966j; ${ }^{20}$ Schonbeck-Temesy, 1966a; ${ }^{21}$ Rechinger, 1966o; ${ }^{22}$ Rechinger, 1966p; ${ }^{23}$ Schonbeck-Temesy, 1966b; ${ }^{24}$ Rechinger, $1966 \mathrm{a}$; 
${ }^{25}$ Rechinger, 1966b; ${ }^{26}$ Rechinger, 1966c; ${ }^{27}$ Rechinger, 1966d; ${ }^{28}$ Rechinger, 1966e; ${ }^{29}$ Rechinger, 1966f; ${ }^{30}$ Rechinger, $1966 \mathrm{~g}$; ${ }^{31}$ Rechinger, 1966k; ${ }^{32}$ Rechinger, 1966l; ${ }^{33}$ Rechinger, 1966m; ${ }^{34}$ Cullen, 1966; ${ }^{35}$ Rechinger, $1966 \mathrm{n} ;{ }^{36}$ Townsend, $1966 \mathrm{n}$; ${ }^{37}$ Rechinger, 1966q; ${ }^{38}$ Rechinger, 1966r; ${ }^{39}$ Rechinger, 1966s; ${ }^{40}$ Rechinger, 1967d; ${ }^{41}$ Schiman-Czeika, 1967; ${ }^{42}$ Schonbeck-Temesy, 1967b; ${ }^{43}$ Patzak \& Rechinger, 1967; ${ }^{44}$ Rechinger 1967a; ${ }^{45}$ Rechinger, 1967c; ${ }^{46}$ Rechinger, 1967b; ${ }^{47}$ Schonbeck-Temesy, 1967a; ${ }^{48}$ Riedl, 1967; ${ }^{49}$ Robson, 1968; ${ }^{50}$ Riedl, 1968; ${ }^{51}$ Polatschek \& Rechinger, 1968b; ${ }^{52}$ Murray, 1968b; ${ }^{53}$ Wendelbo, 1968; ${ }^{54}$ Polatschek \& Rechinger, 1968a; ${ }^{55}$ Murray, 1968a; ${ }^{56}$ Rechinger \& Schiman-Czeika, 1968; ${ }^{57}$ Hedge \& Rechinger, 1968; ${ }^{58}$ Casper, 1969; ${ }^{59}$ Riedl, 1969b; ${ }^{60}$ Riedl, 1969a; ${ }^{61}$ Murray \& Rechinger, 1969; ${ }^{62}$ Rechinger, 1969c; ${ }^{63}$ Rechinger, 1969a; ${ }^{64}$ Rechinger, $1969 \mathrm{~b} ;{ }^{65} \mathrm{Neumann} \&$ Skvortsov, 1969; ${ }^{66}$ Browicz et al., 1969; ${ }^{67}$ Wendelbo, 1970; ${ }^{68}$ Hedge \& Lamond, 1970; ${ }^{69}$ Schonbeck-Temesy, 1970c; ${ }^{70}$ Bor, 1970 ; ${ }^{71}$ Riedl, 1970; ${ }^{72}$ Jansson \& Rechinger, 1970; ${ }^{73}$ Rechinger, 1970; ${ }^{74}$ Vassilczenko, $1970 ;{ }^{75}$ Snogerup, 1971; ${ }^{76}$ Wendelbo, 1971; ${ }^{77}$ Browicz \& Menitsky, 1971; ${ }^{78}$ Dandy, 1971c; ${ }^{79}$ Dandy, 1971d; ${ }^{80}$ Dandy, 1971e; ${ }^{81}$ Dandy, 1971b; ${ }^{82}$ Dandy, 1971f; ${ }^{83}$ Dandy, 1971h; ${ }^{84}$ Dandy, 1971a; ${ }^{85}$ Dandy, 1971i; ${ }^{86}$ Dandy, 1971g; ${ }^{87}$ Browicz, 1971; ${ }^{88}$ Podlech, 1971; ${ }^{90}$ Rechinger, 1972; ${ }^{91}$ Aellen, 1972; ${ }^{93}$ Krisa, 1972b; ${ }^{94}$ Krisa, 1972a; ${ }^{95}$ Peterson, 1972; ${ }^{96}$ Browicz, 1972a; ${ }^{97}$ Browicz, 1972b; ${ }^{98}$ El Hadidi, 1972; ${ }^{99}$ Chrtek, 1972; ${ }^{100}$ SchonbeckTemesy, 1972; ${ }^{101}$ Browicz, 1973b; ${ }^{102}$ Browicz, 1973a; ${ }^{103}$ Rechinger, 1974a; ${ }^{104}$ Wendelbo, 1973; ${ }^{105}$ Chrtek, 1974; ${ }^{106}$ Rechinger, 1974b; ${ }^{108}$ Rechinger \& Schiman-Czeika, 1974; ${ }^{109}$ Rechinger, 1974c; ${ }^{110}$ Wendelbo, 1974; ${ }^{111}$ Browicz \& Zielinski, 1975; ${ }^{112}$ Mathew \& Wendelbo, 1975; ${ }^{113}$ Hedge \& Lamond, 1975a; ${ }^{114}$ Hedge \& Lamond, 1975b; ${ }^{115}$ Chrtek \& Krisa, 1976; ${ }^{116}$ Rechinger, 1976a; ${ }^{117}$ Rechinger, 1976b; ${ }^{118}$ Schotsman, 1976; ${ }^{119}$ Riedl, 1976a; ${ }^{120}$ Riedl, 1976b; ${ }^{121}$ Browicz, 1976; ${ }^{122}$ Rechinger et al., 1977; ${ }^{123}$ Andersen, 1977; ${ }^{124}$ Chrtek \& Krisa, 1977; ${ }^{125}$ Browicz \& Zielinski, 1977; ${ }^{126}$ Renz, 1978; ${ }^{127}$ Rechinger, 1978i; ${ }^{128}$ Rechinger, 1978g; ${ }^{129}$ Rechinger, 1978c; ${ }^{130}$ Rechinger, 1978f; ${ }^{131}$ Rechinger, 1978a; ${ }^{133}$ Rechinger, 1978d; ${ }^{135} \mathrm{Iranshahr}, 1978 \mathrm{~g} ;{ }^{136} \mathrm{Rechinger}$, 1978h; ${ }^{137}$ Rechinger, 1978e; ${ }^{138}$ Rechinger, 1978b; ${ }^{139}$ Dittrich et al., 1980; ${ }^{140}$ Chrtkova-Zertova et al., 1979; ${ }^{142}$ Zielinski, 1979; ${ }^{143}$ Grey-Wilson, $1979 ;{ }^{144}$ Chaudhri et al., $1980 ;{ }^{145}$ Georgiadiou et al., $1980 ;{ }^{147}$ Fischer et al., $1981 ;{ }^{148}$ Browicz, 1981; ${ }^{149}$ Abdallah et al., 1982; ${ }^{150}$ Hedge et al., 1982; ${ }^{151}$ Wendelbo, 1982; ${ }^{152}$ Zielinski, 1982; ${ }^{153}$ Browicz, 1982; ${ }^{154}$ Grierson \& Rechinger, 1982; ${ }^{155}$ Polatschek, 1982; ${ }^{156}$ Rechinger, 1982; ${ }^{157}$ Ali et al., 1984; ${ }^{158}$ Podlech et al., 1986; ${ }^{160}$ Rechinger, 1986a; ${ }^{161}$ Rechinger, $1986 \mathrm{~b}$; ${ }^{162}$ Alava et al., 1987; ${ }^{163}$ Rechinger et al., 1988; ${ }^{164}$ Dittrich et al., 1989; ${ }^{165}$ Rechinger et al., 1990; ${ }^{166}$ Rechinger, 1990b; ${ }^{167}$ Rechinger, 1990a; ${ }^{168}$ Rechinger \& Lack, 1991; ${ }^{169}$ Schmidt, 1992; ${ }^{170}$ Persson, 1992; ${ }^{171}$ Iranshahr et al., 1992; 172 Hedge et al., 1997; ${ }^{173}$ Kukkonen, 1998; ${ }^{174}$ Podlech, 1999; ${ }^{175}$ Podlech et al., 2001; ${ }^{176}$ Ehrendorfer et al., 2005; ${ }^{177}$ Zarre et al., 2008; ${ }^{178}$ Podlech et al., 2010; ${ }^{179}$ Podlech et al., 2012; ${ }^{180}$ Podlech \& Iranshahr, 2015; ${ }^{181}$ Breckle et al., 2015; ${ }^{1}$ Assadi, 1989b; $\stackrel{2}{2}$ Assadi, 1989a; ${ }^{3}$ Khatamsaz, 1989; ${ }^{4}$ Khatamsaz, 1991a; ${ }^{5}$ Khatamsaz, 1991b; ${ }^{6}$ Khatamsaz, 1992; ${ }^{7}$ Akhiani, 1993; ${ }^{8}$ Jamzad, 1993; ${ }^{9}$ Nowroozi, 1993; ${ }^{10}$ Taheri,

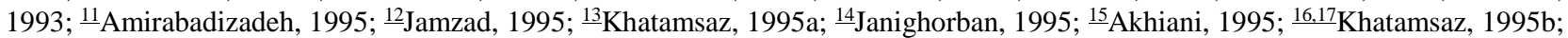

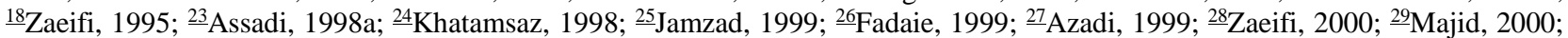

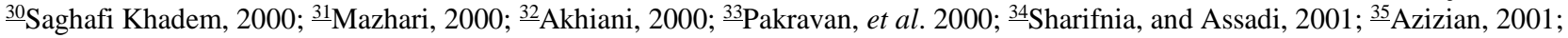
36 Janighorban, 2001; ${ }^{37}$ Moussavi-Allashlou, 2001; ${ }^{38}$ Assadi, 2001; ${ }^{39}$ Khatamsaz, 2002; ${ }^{40}$ Nowroozi, 2002; ${ }^{41}$ Dinarvand, 2002 ; ${ }_{42}$ Hamdi \& Assadi, 2003; ${ }^{43}$ Maassoumi, 2003; ${ }_{4}^{4}$ Fadaie, 2003; ${ }^{45}$ Ghahremaninejad, 2004; ${ }^{46,47}$ Mazhari, 2004; ${ }^{48}$ Azadi, 2005;

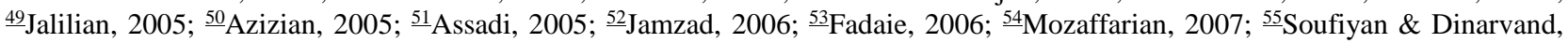

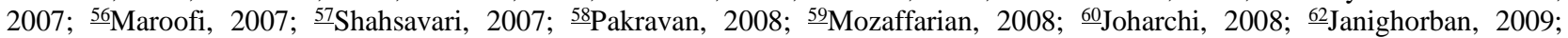
${ }_{63}^{63}$ Ahabeigi, 2009; ${ }^{64}$ Azadi, 2009; ${ }_{55}$ Dinarvand, 2009; ${ }_{66}^{6}$ Ahabeigi and Jalilian, 2010; ${ }^{67}$ Yousef Naanaie, 2010; ${ }_{68}$ Saeidi-Mehrvarz et al., 2011; ${ }^{69}$ Gholamian, 2011; ${ }^{70}$ Safavi, 2011; ${ }^{71}$ Amini Rad, 2011; ${ }^{72,73}$ Dehshiri, 2011; ${ }^{74}$ Maassoumi et al., 2011; ${ }^{75}$ Azadi, R. 2012;

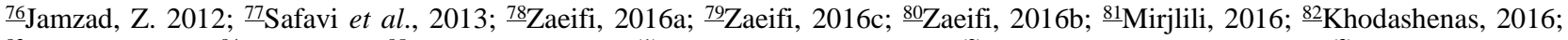
3ㅡㄹehshiri, 2016; ${ }_{44}$ Zare, 2016; ${ }_{85}$ Maassoumi, 2016; (1)Akhani \& Scholz, 1998; (2)Amini Rad \& Scholz, 2011; (3) Amini Rad et al., 2012; ${ }^{(4)}$ Eftekhari et al., 2005; ${ }^{(5)}$ Ghahreman \& Attar, 1999; ${ }^{(6)}$ Ghahremaninejad et al., $2012{ }^{(7)}$ Hamzeh'ee \& Assadi, 2015; ${ }^{(8)}$ Hamzeh'ee \& Naqinezhad, 2009; ${ }^{(9)}$ Hamzeh'ee et al., 2008; (10)Hamzeh'ee, 2000; ${ }^{(11)}$ Joharchi et al., 2011; ${ }^{(12)}$ Naqinejad \& Saeidi Mehrvarz, 2007; ${ }^{(13)}$ Naqinezhad et al., 2007; ${ }^{(14)}$ Thiv, 2016.

در مجموع فلور نهاندانگان در ايران شامل حدود

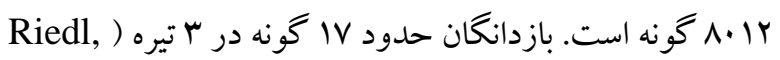

1963a; 1965a,b; 1968; Assadi, 1998b; Ghahremaninejad, 1999 و سرخس ها در مجموع حدود

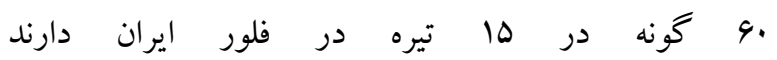

Ghahremaninejad, 1999; Khoshravesh et al., ) 2009). از خزهها نيز حدود ع كاه گونه از ايران گزارش شدهاست (Ghahremaninejad et al., 2016) بنابراين فلور ايران به طور تقريبى داراى A\&Y^ كونه است.

با توجه به اين كه بررسىهاى دقيق سردههاى مختلف اغلب منجر به شناسايى كونه هاى جديدى براى ايران شدهاست (براى

مثال: Nejad Falatoury et al., 2012; 2015; 2016

تخمين مىزنيم كه حدود · ا درصد فلور ايران هنوز ناشناخته-

\section{نتيجه كيرى}

از بسا تيرهُ نهاندانهاى كه براساس نظام ردهبندى APG IV در

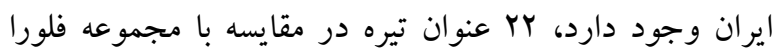

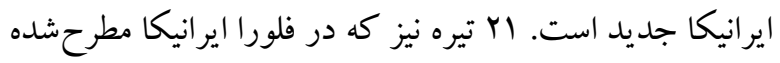

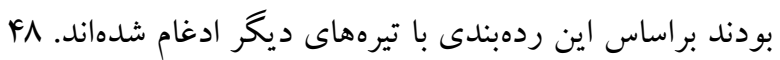

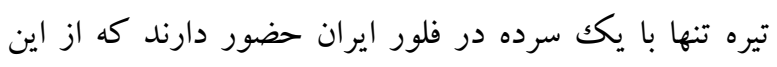
تعداد · ا تيره، مونو تيبيكك هستند. 


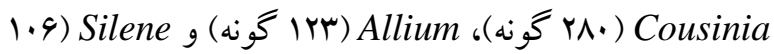

$$
\begin{aligned}
& \text { كونه). } \\
& \text { سباسگزارى } \\
& \text { نغارند گان از آقاى بابكك دبير (دانشخاه گيلان) براى كمكك در }
\end{aligned}
$$

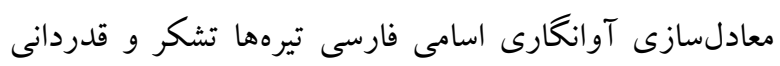

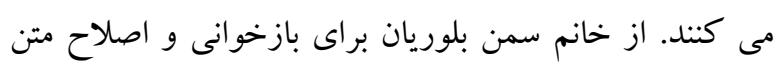

$$
\begin{aligned}
& \text { اوليه، خانم مريم نوروزى براى همكارى در تهيئ فهرست سرده - }
\end{aligned}
$$

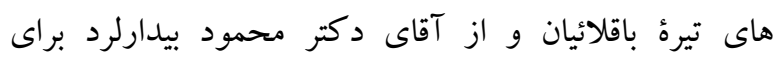

$$
\begin{aligned}
& \text { همكارى در تهيؤ فهرست سردههاى تيره گندميان سباسگز اريم. }
\end{aligned}
$$

\section{References}

Abdallah, M.S., de Wit, H.C.D. and Rechinger, K.H. 1982. Rosaceae II. - In: Rechinger, K.H. (ed.): Flora Iranica, Lfg. 149. - Akad. Druck- und Verlagsanstalt, Graz.

Aghabeigi, F. 2009. Morinaceae. - In: Assadi, M. et al. (eds.): Flora of Iran, No. 63. - RIFR, Tehran.

Aghabeigi, F. and Jalilian, N. 2010. Campanulaceae. - In: Assadi, M. et al. (eds.): Flora of Iran, No. 66. - RIFR, Tehran.

Akhani, H. and Scholz, H. 1998. Studies on the flora and vegetation of the Golestan National Park, NE Iran. II. A new Poa and some new and noteworthy grass records for Iran. - Edinb. J. Bot. 55 (3): 443-453.

Akhiani, Kh. 1993. Zygophyllaceae. - In: Assadi, M. et al. (eds.): Flora of Iran, No. 7. - RIFR, Tehran.

Akhiani, Kh. 1995. Thymelaceae. - In: Assadi, M. et al. (eds.): Flora of Iran, No. 15. - RIFR, Tehran.

Akhiani, Kh. 2000. Crassulaceae. - In: Assadi, M. et al. (eds.): Flora of Iran, No. 32. - RIFR, Tehran.

Alava, R., Chamberlain, D.F., Engstrand, L., Hedge, I.C., Hermstadt, I., Heyn, C.C., Lamond, J.M., Leute, G.H., Mandenova, I., Peev, D., Pimenov, M.G., Rechinger, K.H., Snogerup, S. and Tamamschian, S.G. 1987. Umbelliferae. - In: Rechinger, K.H. (ed.): Flora Iranica 162. - Akad. Druck- und Verlagsanstalt, Graz.

Ali, S.I., Browicz, K., Chrtková-Zertová, A., Heller, D., Heyn, C.C., Rechinger, K.H., Thulin, M. and Vassilczenko, I.T. 1984. Papilionaceae II. - In: Rechinger, K.H. (ed.): Flora Iranica, Lfg. 157. - Akad. Druck- und Verlagsanstalt, Graz.

Amini Rad, M. 2011. Cyperaceae. - In: Assadi, M. et al. (eds.): Flora of Iran, No. 71. - RIFR, Tehran.

$$
\begin{aligned}
& \text { است؛ به عبارت ديخر تعداد واقعى كورموفيتهاى ايران }
\end{aligned}
$$

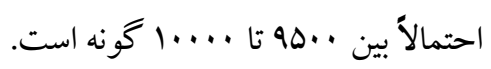

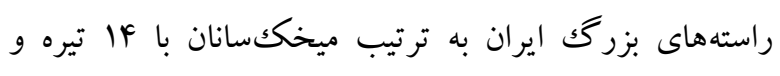

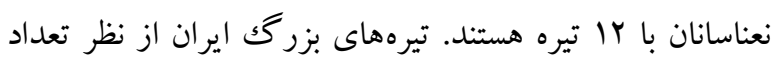

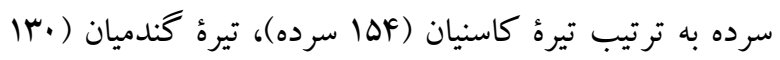

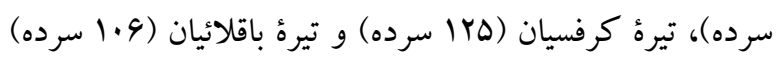

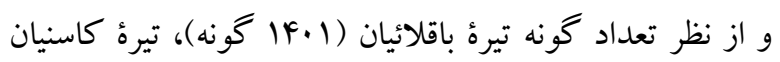

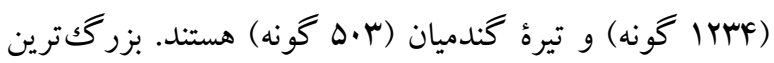

$$
\begin{aligned}
& \text { سردهاى ايران به ترتيب عبارتند از Astragalus ( •rیر كونه)، }
\end{aligned}
$$

Amini Rad, M. and Scholz, H. 2011. Urochloa panicoides and a subspecies of Eragrostis cilianensis, new to the flora of Iran. - Rostaniha 12 (2): 195-198.

Amini Rad, M., Sonboli, A. and Hadian, J. 2012. Hierochloe odorata (Poaceae), a new report from Iran. - Iran. J. Bot. 18 (2): 224-225.

Amirabadizadeh, H. 1995. Frankeniaceae. - In: Assadi, M. et al. (eds.): Flora of Iran, No. 11. RIFR, Tehran.

Andersen, J.S. 1977. Cucurbitaceae. - In: Rechinger, K.H. (ed.): Flora Iranica, Lfg. 123. Akad. Druck- und Verlagsanstalt, Graz.

APG I. 1998. An ordinal classification for the families of flowering plants. - Annals of the Missouri Botanical Garden 85: 531-553.

APG II. 2003. An update of the Angiosperm Phylogeny Group classification for the orders and families of flowering plants: APG II. - Botanical Journal of the Linnean Society 141: 399-436.

APG III. 2009. An update of the Angiosperm Phylogeny Group classification for the orders and families of flowering plants: APG III. - Botanical Journal of the Linnean Society 161: 105-121.

APG IV. 2016. An update of the Angiosperm Phylogeny Group classification for the orders and families of flowering plants: APG IV. - Botanical Journal of the Linnean Society 181(1): 1-20.

Assadi, M. (ed.), 1989-2016: Flora of Iran 1-85. RIFR, Tehran.

Assadi, M. 1989a. Araceae. - In: Assadi, M. et al. (eds.): Flora of Iran, No. 2. - RIFR, Tehran.

Assadi, M. 1989b. Tamaricaceae. - In: Assadi, M. et al. (eds.): Flora of Iran, No. 1. - RIFR, Tehran. 
Assadi, M. 1998a. Grossulariaceae. - In: Assadi, M. et al. (eds.): Flora of Iran, No. 23. - RIFR, Tehran.

Assadi, M. 1998b. Pinaceae, Taxacae, Cupressaceae and Ephedraceae. - In: Assadi, M. et al. (eds.): Flora of Iran, Nos. 19-22. - RIFR, Tehran.

Assadi, M. 2001. Chenopodiaceae. - In: Assadi, M. et al. (eds.): Flora of Iran, No. 38. - RIFR, Tehran.

Assadi, M. 2005. Plumbaginaceae. - In: Assadi, M. et al. (eds.): Flora of Iran, No. 51. - RIFR, Tehran.

Azadi, R. 1999. Guttiferae. - In: Assadi, M. et al. (eds.): Flora of Iran, No. 27. - RIFR, Tehran.

Azadi, R. 2005. Oleaceae. - In: Assadi, M. et al. (eds.): Flora of Iran, No. 48. - RIFR, Tehran.

Azadi, R. 2009. Berberidaceae. - In: Assadi, M. et al. (eds.): Flora of Iran, No. 64. - RIFR, Tehran.

Azadi, R. 2012. Amaranthaceae. - In: Assadi, M. et al. (eds.): Flora of Iran, No. 75. - RIFR, Tehran.

Azizian, D. 2001. Moraceae. - In: Assadi, M. et al. (eds.): Flora of Iran, No. 35. - RIFR, Tehran.

Azizian, D. 2005. Onagraceae. - In: Assadi, M. et al. (eds.): Flora of Iran, No. 50. - RIFR, Tehran.

Bor, N.L. 1970. Graminae. - In: Rechinger, K.H. (ed.), Flora Iranica. Lfg. 70. - Akad. Druck- und Verlagsanstalt, Graz.

Breckle, S.-W., Vitek, E., Akhani, H., Ghahremaninejad, F., Joharchi, M.R., Mehrabian, A.R., Mozaffarian, V., Naderi, R. and Ranjbar, M. 2015. Simaroubaceae. - In: Rechinger K.H. (ed.): Flora Iranica, Lfg. 181. Naturhistorisches Museum, Wien.

Browicz, K. 1971. Staphyleaceae. - In: Rechinger, K.H. (ed.): Flora Iranica, Lfg. 87. - Akad. Druckund Verlagsanstalt, Graz.

Browicz, K. 1972a. Betulaceae. - In: Rechinger, K.H. (ed.): Flora Iranica, Lfg. 96. - Akad. Druckund Verlagsanstalt, Graz.

Browicz, K. 1972b. Corylaceae. - In: Rechinger, K.H. (ed.): Flora Iranica, Lfg. 97. - Akad. Druckund Verlagsanstalt, Graz.

Browicz, K. 1973.b Podophyllaceae. - In: Rechinger, K.H. (ed.): Flora Iranica, Lfg. 101. Akad. Druck- und Verlagsanstalt, Graz.

Browicz, K. 1973a. Araliaceae. - In: Rechinger, K.H. (ed.): Flora Iranica, Lfg. 102. - Akad. Druckund Verlagsanstalt, Graz.

Browicz, K. 1976. Juglandaceae. - In: Rechinger, K.H. (ed.): Flora Iranica, Lfg. 121. - Akad. Druckund Verlagsanstalt, Graz.
Browicz, K. 1981. Tiliaceae. - In: Rechinger, K.H. (ed.): Flora Iranica, Lfg. 148. - Akad. Druck- und Verlagsanstalt, Graz.

Browicz, K. 1982. Moraceae. - In: Rechinger, K.H. (ed.): Flora Iranica, Lfg. 153. - Akad. Druck- und Verlagsanstalt, Graz.

Browicz, K. and Menitsky, G.L. 1971. Fagaceae. - In: Rechinger, K.H. (ed.): Flora Iranica, Lfg. 77. Akad. Druck- und Verlagsanstalt, Graz.

Browicz, K. and Zielinski, J. 1975. Berberidaceae. - In: Rechinger, K.H. (ed.): Flora Iranica, Lfg. 111. - Akad. Druck- und Verlagsanstalt, Graz.

Browicz, K. and Zielinski, J. 1977. Rhamnaceae. - In: Rechinger, K.H. (ed.): Flora Iranica, Lfg. 125. - Akad. Druck- und Verlagsanstalt, Graz.

Browicz, K., Fröhner, S., Gilli, A., Nordborg, G., Riedl, H., Schiman-Czeika, H., SchönbeckTemesy, E. and Vassilczenko, L.T. 1969. Rosaceae I. - In: Rechinger, K.H. (ed.): Flora Iranica, Lfg. 66. - Akad. Druck- und Verlagsanstalt, Graz.

Casper, S. J. 1969. Lentibulariaceae. - In: Rechinger, K.H. (ed.): Flora Iranica, Lfg. 58. Akad. Druck- und Verlagsanstalt, Graz.

Chaudhri, M.N., Ratter, J.A. and Rechinger, K.H. 1980. Caryophyllaceae I -Paronychioideae. In: Rechinger, K.H. (ed.): Flora Iranica, Lfg. 144. Akad. Druck- und Verlagsanstalt, Graz.

Chrtek, J. 1972. Frankeniaceae. - In: Rechinger, K.H. (ed.): Flora Iranica, Lfg. 99. - Akad. Druckund Verlagsanstalt, Graz.

Chrtek, J. 1974. Urticaceae. - In: Rechinger, K.H. (ed.): Flora Iranica, Lfg. 105. - Akad. Druck- und Verlagsanstalt, Graz.

Chrtek, J. and Krisa, B. 1976. Nyctaginaceae. In: Rechinger, K.H. (ed.): Flora Iranica, Lfg. 115. Akad. Druck- und Verlagsanstalt, Graz.

Chrtek, J. and Krisa, B. 1977. Polygalaceae. - In: Rechinger, K.H. (ed.): Flora Iranica, Lfg.124. Akad. Druck- und Verlagsanstalt, Graz.

Chrtková-Zertová, A., van der Maesen, L.J.G. and Rechinger, K.H. 1979. Papilionaceae I: Vicieae. - In: Rechinger, K.H. (ed.): Flora Iranica, Lfg. 140. - Akad. Druck- und Verlagsanstalt, Graz.

Cullen, J. 1966. Papaveraceae. - In: Rechinger, K.H. (ed.): Flora Iranica, Lfg. 34. - Akad. Druckund Verlagsanstalt, Graz.

Dandy, J. E. 1971a. Ruppiaceae. - In: Rechinger, K.H. (ed.): Flora Iranica, Lfg. 84. - Akad. Druckund Verlagsanstalt, Graz. 
Dandy, J. E. 1971b. Zosteraceae. - In: Rechinger, K.H. (ed.): Flora Iranica, Lfg. 81. - Akad. Druckund Verlagsanstalt, Graz.

Dandy, J.E. 1971c. Alismataceae. - In: Rechinger, K.H. (ed.): Flora Iranica, Lfg. 78. - Akad. Druckund Verlagsanstalt, Graz.

Dandy, J.E. 1971d. Butomaceae. - In: Rechinger, K.H. (ed.): Flora Iranica, Lfg. 79. - Akad. Druckund Verlagsanstalt, Graz.

Dandy, J.E. 1971e. Hydrocharitaceae. - In: Rechinger, K.H. (ed.): Flora Iranica, Lfg. 80. Akad. Druck- und Verlagsanstalt, Graz.

Dandy, J.E. 1971f. Juncaginaceae. - In: Rechinger, K.H. (ed.): Flora Iranica, Lfg. 82. - Akad. Druckund Verlagsanstalt, Graz.

Dandy, J.E. 1971g. Najadaceae. - In: Rechinger, K.H. (ed.): Flora Iranica, Lfg. 86. - Akad. Druckund Verlagsanstalt, Graz.

Dandy, J.E. 1971h. Potamogetonaceae. - In: Rechinger, K.H. (ed.): Flora Iranica, Lfg. 83. Akad. Druck- und Verlagsanstalt, Graz.

Dandy, J.E. 1971i. Zannichelliaceae. - In: Rechinger, K.H. (ed.): Flora Iranica, Lfg. 85. Akad. Druck- und Verlagsanstalt, Graz.

Dehshiri, M.M. 2011. Loranthaceae and Viscaceae. - In: Assadi, M. et al. (eds.): Flora of Iran, Nos. 7273. - RIFR, Tehran.

Dehshiri, M.M. 2016. Cornaceae. - In: Assadi, M. et al. (eds.): Flora of Iran, No. 83. - RIFR, Tehran.

Dinarvand, M. 2002. Apocynaceae. - In: Assadi, M. et al. (eds.): Flora of Iran, No. 41. - RIFR, Tehran.

Dinarvand, M. 2009. Caryophyllaceae: Paronychioideae. - In: Assadi, M. et al. (eds.): Flora of Iran, No. 65. - RIFR, Tehran.

Dittrich, M., Nordenstam, B. and Rechinger, K.H. 1989. Compositae VII. - In: Rechinger, K.H. (ed.): Flora Iranica, Lfg. 164, - Akad. Druck- und Verlagsanstalt, Graz.

Dittrich, M., Petrak, F., Rechinger, K.H. and Wagenitz, G. 1979. Compositae III: Cynareae. In: Rechinger, K.H. (ed.): Flora Iranica, Lfg. 139a. - Akad. Druck- und Verlagsanstalt, Graz.

Dittrich, M., Petrak, F., Rechinger, K.H. and Wagenitz, G. 1980. Compositae III: Cynareae. In: Rechinger, K.H. (ed.): Flora Iranica, Lfg. 139b. - Akad. Druck- und Verlagsanstalt, Graz.

Eftekhari, Z., Filehkesh, E., Bakhshi, Gh. and Assadi, M. 2005. Leymus tianschanicus (Poaceae), a new name for the flora of Iran. - Iran. Journ. Bot. 11 (1): 85-87.
Ehrendorfer, F., Schönbeck-Temesy, E., Puff, C. and Rechinger, W. 2005. Rubiaceae. - In: Rechinger, K.H. (ed.): Flora Iranica 176. Naturhistorisches Museum, Wien.

El Hadidi, M.N. 1972. Zygophyllaceae. - In: Rechinger, K.H. (ed.): Flora Iranica, Lfg. 98. Akad. Druck- und Verlagsanstalt, Graz.

Fadaie, F. 1999. Nyctaginaceae. - In: Assadi, M. et al. (eds.): Flora of Iran, No. 26. - RIFR, Tehran.

Fadaie, F. 2003. Aizoaceae. - In: Assadi, M. et al. (eds.): Flora of Iran, No. 44. - RIFR, Tehran.

Fadaie, F. 2006. Molluginaceae. - In: Assadi, M. et al. (eds.): Flora of Iran, No. 53. - RIFR, Tehran.

Fischer M.A., Grau J., Huber-Morath A., Rechinger K.H., Wendelbo P., Yeo P.F. 1981. Scrophulariaceae I. - In: Rechinger, K.H. (ed.): Flora Iranica, Lfg. 147. - Akad. Druck- und Verlagsanstalt, Graz.

Georgiadiou, E., Lack, H.W., Merxüller, H., Rechinger, K.H. and Wagenitz, G. 1979. Compositae IV: Inuleae. - In: Rechinger, K.H. (ed.): Flora Iranica, Lfg. 145. - Akad. Druck- und Verlagsanstalt, Graz.

Ghahreman, A. and Attar, F. 1999. Biodiversity of plant species in Iran. - Tehran University press, Tehran.

Ghahremaninejad, F. 1999. Flora of Gilan. Vol. 1: Pteriodophytes and Gymnosperms. -Gilan University Press, Rasht (in Persian).

Ghahremaninejad, F. 2004. Caesalpiniaceae. - In: Assadi, M. et al. (eds.): Flora of Iran, No. 45. RIFR, Tehran.

Ghahremaninejad, F. 2015. Notes about Astragalus (Leguminosae) in Iran. - Ann. Naturhist. Mus. Wien, B 117: 279-281.

Ghahremaninejad, F., Joharchi, M. and Vitek, E. 2012. New plant records for Khorassan province, Iran, V; with complementary notes to its flora. Ann. Naturhist. Mus. Wien, B 114: 59-94.

Ghahremaninejad, F., Shirzadian, S. and Fereidounfar, S. 2016. An updated list of the bryological literature on Iran. - Ann. Naturhist. Mus. Wien, B 118: 181-188.

Gholamian, F. 2011. Cistaceae. - In: Assadi, M. et al. (eds.): Flora of Iran, No. 69. - RIFR, Tehran.

Grey-Wilson, Ch. 1979. Balsaminaceae. - In: Rechinger, K.H. (ed.): Flora Iranica, Lfg. 143. Akad. Druck- und Verlagsanstalt, Graz.

Grierson, A.J.C. and Rechinger, K.H. 1982. Compositae V - Astereae. - In: Rechinger, K.H. (ed.): Flora Iranica, Lfg. 154. - Akad. Druck- und Verlagsanstalt, Graz. 
101/1.1 Hamdi, S.M.M. and Assadi, M. 2003. Typhaceae. - In: Assadi, M. et al. (eds.): Flora of Iran, No. 42. - RIFR, Tehran.

Hamzeh'ee, B. and Assadi, M. 2015. Taxonomical notes on the genus Piptatherum P. Beauv. (Poaceae) in Iran. - Iran. J. Bot. 21 (1): 1-9.

Hamzeh'ee, B. 2000. Some new and noteworthy plant records from Iran. - Iran. J. Bot. 8 (2): 271 277.

Hamzeh'ee, B. and Naqinezhad, A. 2009. Arthraxon P. Beauv (Gramineae) and Carex caryophyllea (Cyperceae): New genus and species records from Iran. - Iran. J. Bot. 15 (1): 68-71.

Hamzeh'ee, B., Ghahremaninejad, F., Bidar Lord, M. and Attar, F. 2008. Ventenata Koeler, a new genus (Gramineae: Pooideae) record for Iran. Iran. J. Bot. 14 (2): 105-107.

Hedge, I.C. and Lamond, J.M. 1970. Capparidaceae. - In: Rechinger, K.H. (ed.): Flora Iranica, Lfg. 68. - Akad. Druck- und Verlagsanstalt, Graz.

Hedge, I.C. and Lamond, J.M. 1975a. Aizoaceae. - In: Rechinger, K.H. (ed.): Flora Iranica, Lfg. 113. - Akad. Druck- und Verlagsanstalt, Graz.

Hedge, I.C. and Lamond, J.M. 1975b. Molluginaceae. - In: Rechinger, K.H. (ed.): Flora Iranica, Lfg. 114. - Akad. Druck- und Verlagsanstalt, Graz.

Hedge, I.C. and Rechinger, K.H. 1968. Cruciferae. - In: Rechinger, K.H. (ed.): Flora Iranica, Lfg. 57. - Akad. Druck- und Verlagsanstalt, Graz.

Hedge, I.C., Akhani, H., Freitag, H., KotheHeinrich, G., Podlech, D., Rilke, S. and Uotila, P. 1997. Chenopodiaceae. - In: Rechinger, K.H. (ed.): Flora Iranica, Lfg. 172. - Akad. Druck- und Verlagsanstalt, Graz.

Hedge, I.C., Ietswaart, J.H., Jalas, J., Mennema, J., Rechinger, K.H. and Seybold, S. 1982. Labiatae. - In: Rechinger, K.H. (ed.): Flora Iranica, Lfg. 150. - Akad. Druck- und Verlagsanstalt, Graz.

Iranshahr, M. 1978. Morinaceae. - In: Rechinger, K.H. (ed.): Flora Iranica, Lfg. 135. - Akad. Druckund Verlagsanstalt, Graz.

Iranshahr, M., Rechinger, K.H. and Riedl, H. 1992. Ranunculaceae. - In: Rechinger, K.H. (ed.): Flora Iranica, Lfg. 171. - Akad. Druck- und Verlagsanstalt, Graz.

Jalilian, N. 2005. Polygalaceae. - In: Assadi, M. et al. (eds.): Flora of Iran, No. 49. - RIFR, Tehran.

Jamzad, Z. 1993. Dipsacaceae. - In: Assadi, M. et al. (eds.): Flora of Iran, No. 8. - RIFR, Tehran.
Jamzad, Z. 1995. Saxifragaceae. - In: Assadi, M. et al. (eds.): Flora of Iran, No. 12. - RIFR, Tehran.

Jamzad, Z. 1999. Primulaceae. - In: Assadi, M. et al. (eds.): Flora of Iran, No. 25. - RIFR, Tehran.

Jamzad, Z. 2006. Verbenaceae. - In: Assadi, M. et al. (eds.): Flora of Iran, No. 52. - RIFR, Tehran.

Jamzad, Z. 2012. Lamiaceae. - In: Assadi, M. et al. (eds.): Flora of Iran, No. 76. - RIFR, Tehran.

Janighorban, M. 1995. Plantaginaceae. - In: Assadi, M. et al. (eds.): Flora of Iran, No. 14. RIFR, Tehran.

Janighorban, M. 2001. Urticaceae. - In: Assadi, M. et al. (eds.): Flora of Iran, No. 36. - RIFR, Tehran.

Janighorban, M. 2009. Geraniaceae. - In: Assadi, M. et al. (eds.): Flora of Iran, No. 62. - RIFR, Tehran.

Jansson, C.A. and Rechinger, K.H. 1970. Crassulaceae. - In: Rechinger, K.H. (ed.): Flora Iranica, Lfg. 72. - Akad. Druck- und Verlagsanstalt, Graz.

Joharchi, M. 2008. Rutaceae. - In: Assadi, M. et al. (eds.): Flora of Iran, No. 60. - RIFR, Tehran.

Joharchi, M., Ghahremaninejad, F. and Vitek, E. 2011. New plant records for Khorassan province, Iran, IV; with complementary notes to its flora. Ann. Naturhist. Mus. Wien, B 112: 329-367.

Khatamsaz, M. 1989. Anacardiaceae. - In: Assadi, M. et al. (eds.): Flora of Iran, No. 3. - RIFR, Tehran.

Khatamsaz, M. 1991a. Ulmaceae. - In: Assadi, M. et al. (eds.): Flora of Iran, No. 4. - RIFR, Tehran.

Khatamsaz, M. 1991b. Violaceae. - In: Assadi, M. et al. (eds.): Flora of Iran, No. 5. - RIFR, Tehran.

Khatamsaz, M. 1992. Rosaceae. - In: Assadi, M. et al. (eds.): Flora of Iran, No. 6. - RIFR, Tehran.

Khatamsaz, M. 1995a. Caprifoliaceae. - In: Assadi, M. et al. (eds.): Flora of Iran, No. 13. RIFR, Tehran.

Khatamsaz, M. 1995b. Gentianaceae and Menyanthaceae. - In: Assadi, M. et al. (eds.): Flora of Iran, Nos. 16-17. - RIFR, Tehran.

Khatamsaz, M. 1998. Solanaceae. - In: Assadi, M. et al. (eds.): Flora of Iran, No. 24. - RIFR, Tehran.

Khatamsaz, M. 2002. Boraginaceae. - In: Assadi, M. et al. (eds.): Flora of Iran, No. 39. - RIFR, Tehran.

Khodashenas, M. 2016. Oxalidaceae. - In: Assadi, M. et al. (eds.): Flora of Iran, No. 82. - RIFR, Tehran. 
Khoshravesh, R., Akhani, H., Eskandari, M., Greuter, W. 2009. Ferns and fern allies of Iran. Rostaniha 10 (Supplement 1).

Kolbadi, A. 2009. Equisetaceae. - In: Assadi, M. et al. (eds.): Flora of Iran, No. 61. - RIFR, Tehran.

Krisa, B. 1972a. Monotropaceae. - In: Rechinger, K.H. (ed.): Flora Iranica, Lfg. 94. - Akad. Druckund Verlagsanstalt, Graz.

Krisa, B. 1972b. Pyrolaceae. - In: Rechinger, K.H. (ed.): Flora Iranica, Lfg. 93. - Akad. Druck- und Verlagsanstalt, Graz.

Kukkonen, I. 1998. Cyperaceae. - In: Rechinger, K.H. (ed.): Flora Iranica, Lfg. 173. - Akad. Druckund Verlagsanstalt, Graz.

Maassoumi, A.A. 2003. Papilionaceae (Astragalus I). - In: Assadi, M. et al. (eds.): Flora of Iran, No. 43. - RIFR, Tehran.

Maassoumi, A.A. 2016. Papilionaceae (Astragalus II). - In: Assadi, M. et al. (eds.): Flora of Iran, No. 85. - RIFR, Tehran.

Maassoumi, A.A., Assadi, M. and Hamdi, S.M.M. 2011. Salicaceae. - In: Assadi, M. et al. (eds.): Flora of Iran, No. 74. - RIFR, Tehran.

Majid, M. 2000. Aristolochiaceae. - In: Assadi, M. et al. (eds.): Flora of Iran, No. 29. - RIFR, Tehran.

Maroofi, H. 2007. Podophyllaceae. - In: Assadi, M. et al. (eds.): Flora of Iran, No. 56. - RIFR, Tehran.

Mathew, B. and Wendelbo, P. 1975. Iridaceae. In: Rechinger, K.H. (ed.): Flora Iranica, Lfg. 112. Akad. Druck- und Verlagsanstalt, Graz.

Mazhari, N. 2000. Iridaceae. - In: Assadi, M. et al. (eds.): Flora of Iran, No. 31. - RIFR, Tehran.

Mazhari, N. 2004. Ixioliriaceae and Amaryllidaceae. - In: Assadi, M. et al. (eds.): Flora of Iran, Nos. 46-47. - RIFR, Tehran.

Mirjlili, S.A. 2016. Punicaceae. - In: Assadi, M. et al. (eds.): Flora of Iran, No. 81. - RIFR, Tehran.

Moussavi-Allashlou, E. 2001. Valerianaceae. - In: Assadi, M. et al. (eds.): Flora of Iran, No. 37. RIFR, Tehran.

Mozaffarian, V. 2007. Umbelliferae. - In: Assadi, M. et al. (eds.): Flora of Iran, No. 54. - RIFR, Tehran.

Mozaffarian, V. 2008. Compositae: Anthemideae and Echinopeae. - In: Assadi, M. et al. (eds.): Flora of Iran, No. 59. - RIFR, Tehran.

Murray, E. 1968a. Elaeagnaceae. - In: Rechinger, K.H. (ed.): Flora Iranica, Lfg. 55. - Akad. Druckund Verlagsanstalt, Graz.
Murray, E. 1968b. Oleaceae. - In: Rechinger, K.H. (ed.): Flora Iranica, Lfg. 52. - Akad. Druck- und Verlagsanstalt, Graz.

Murray, E. and Rechinger, K.H. 1969. Aceraceae. - In: Rechinger, K.H. (ed.): Flora Iranica 61. - Akad. Druck- und Verlagsanstalt, Graz.

Naqinejad, A. and Saeidi Mehrvarz, Sh. 2007. Some new records for Iran and Flora Iranica area collected from Boujagh National Park, N. Iran. Iran. J. Bot. 13 (2): 112-119.

Naqinezhad, A.R., Saeidi Mehrvarz, Sh., Djavadi, S.B. and Ramezankhah, S. 2007. A new genus record of Asteraceae (Soliva pterosperma) for the flora of Iran. - Iran. J. Bot. 13 (2): 104-106.

Nejad Falatoury, A., Assadi, M. and Ghahremaninejad. F. 2015. A new species of Gypsophila (Caryophyllaceae) from Iran. Phytotaxa 222(4): 276-282.

Nejad Falatoury, A., Assadi, M. and Ghahremaninejad. F. 2016. Gypsophila yazdiana (Caryophyllaceae), a New Species from Iran. Novon 24(4): 347-351.

Nejad Falatoury, A., Pakravn, M. and Tavassoli, A. 2012. A new species and some notes on the genus Nonea (Boraginaceae) in Iran. - Feddes repert. 122(7-8): 425-432.

Neumann, A. and Skvortsov, A.K. 1969. Salicaceae. - In: Rechinger, K.H. (ed.): Flora Iranica, Lfg. 65. - Akad. Druck- und Verlagsanstalt, Graz.

Nowroozi, M. 1993. Resedaceae. - In: Assadi, M. et al. (eds.): Flora of Iran, No. 9. - RIFR, Tehran.

Nowroozi, M. 2002. Convolvulaceae. - In: Assadi, M. et al. (eds.): Flora of Iran, No. 40. - RIFR, Tehran.

Olson, M.E., Gaskin, J.F. and Ghahremaninejad, F. 2003. Stem anatomy is congruent with molecular phylogenies placing Hypericopsis persica in Frankenia (Frankeniaceae): comments on vasicentric tracheids. - Taxon 52: 525-532.

Pakravan, M. 2008. Malvaceae. - In: Assadi, M. et al. (eds.): Flora of Iran, No. 58. - RIFR, Tehran.

Pakravan, M., Jalilian, N. and Neamati, M. 2000. Papilionaceae (Vicieae). - In: Assadi, M. et al. (eds.): Flora of Iran, No. 33. - RIFR, Tehran.

Patzak, A. and Rechinger, K.H. 1965. Plantaginaceae. - In: Rechinger, K.H. (ed.): Flora Iranica, Lfg. 15. - Akad. Druck- und Verlagsanstalt, Graz. 
Patzak, A. Rechinger, K.H., 1967. Verbenaceae. In: Rechinger, K.H. (ed.): Flora Iranica, Lfg. 43. Akad. Druck- und Verlagsanstalt, Graz.

Persson, K. 1992. Liliaceae III. - In: Rechinger, K.H. (ed.): Flora Iranica, Lfg. 170. - Akad. Druckund Verlagsanstalt, Graz.

Peterson, B. 1972. Thymeleaceae. - In: Rechinger, K.H. (ed.): Flora Iranica, Lfg. 95. - Akad. Druckund Verlagsanstalt, Graz.

Podlech, D. 1971. Sphenocleaceae. - In: Rechinger, K.H. (ed.): Flora Iranica, Lfg. 88. Akad. Druck- und Verlagsanstalt, Graz.

Podlech, D. 1999. Papilionaceae III: Astragaleae: Astragalus I. - In: Rechinger, K.H. (ed.): Flora Iranica, Lfg. 174. - Akad. Druck- und Verlagsanstalt, Graz.

Podlech, D. and Iranshahr, M. 2015. Scrophulariaceae II, Antirrrhineae. - In: Rechinger K.H. (ed.): Flora Iranica, Lfg. 180. Naturhistorisches Museum, Wien.

Podlech, D., Huber-Morath, A., Iranshahr, M. and Rechinger, K.H. 1986. Compositae VI: Anthemideae. - In: Rechinger, K.H. (ed.): Flora Iranica, Lfg. 158. - Akad. Druck- und Verlagsanstalt, Graz.

Podlech, D., Maassoumi, A.A. and Zarre Sh. 2012. Papilionaceae VII, Astragalus V. - In: Rechinger K.H. (ed.): Flora Iranica, Lfg. 179. Naturhistorisches Museum, Wien.

Podlech, D., Zarre, Sh. and Maassoumi, A.A. 2001. Papilionaceae IV, Astragalus II. - In: Rechinger, K.H. (ed.): Flora Iranica, Lfg. 175. Naturhistorisches Museum, Wien.

Podlech, D., Zarre, Sh., Maassoumi, A.A., Ekici, M. and Sytin, A. 2010. Papilionaceae VI, Astragalus IV. - In: Rechinger K.H. (ed.): Flora Iranica, Lfg. 178. - Naturhistorisches Museum, Wien.

Polatschek, A. 1982. Santalaceae. - In: Rechinger, K.H. (ed.): Flora Iranica, Lfg. 155. - Akad. Druckund Verlagsanstalt, Graz.

Polatschek, A. and Rechinger, K.H. 1968a. Cornaceae. - In: Rechinger, K.H. (ed.): Flora Iranica, Lfg. 54. - Akad. Druck- und Verlagsanstalt, Graz.

Polatschek, A. and Rechinger, K.H. 1968b. Lythraceae. - In: Rechinger, K.H. (ed.): Flora Iranica, Lfg. 51. - Akad. Druck- und Verlagsanstalt, Graz.

Raven, P.H. 1964. Onagraceae. - In: Rechinger, K.H. (ed.): Flora Iranica, Lfg. 7. - Akad. Druckund Verlagsanstalt, Graz.
Rechinger, K.H. (ed.), 1963-2012: Flora Iranica 1179. - 1-174 Akad. Druck- und Verlagsanstalt, Graz.; 175-179 Naturhistorisches Museum, Wien.

Rechinger, K.H. 1963. Convolvulaceae. - In: Rechinger, K.H. (ed.): Flora Iranica, Lfg. 1. - Akad. Druck- und Verlagsanstalt, Graz.

Rechinger, K.H. 1966a. Acanthaceae. - In: Rechinger, K.H. (ed.): Flora Iranica, Lfg. 24. Akad. Druck- und Verlagsanstalt, Graz.

Rechinger, K.H. 1966b. Aquifoliaceae. - In: Rechinger, K.H. (ed.): Flora Iranica, Lfg. 25. Akad. Druck- und Verlagsanstalt, Graz.

Rechinger, K.H. 1966c. Aristolochiaceae. - In: Rechinger, K.H. (ed.): Flora Iranica, Lfg. 26. Akad. Druck- und Verlagsanstalt, Graz.

Rechinger, K.H. 1966d. Buxaceae. - In: Rechinger, K.H. (ed.): Flora Iranica, Lfg. 27. Akad. Druck- und Verlagsanstalt, Graz.

Rechinger, K.H. 1966e. Ceratophyllaceae. - In: Rechinger, K.H. (ed.): Flora Iranica, Lfg. 28. Akad. Druck- und Verlagsanstalt, Graz.

Rechinger, K.H. 1966f. Datiscaceae. - In: Rechinger, K.H. (ed.): Flora Iranica, Lfg. 29. Akad. Druck- und Verlagsanstalt, Graz.

Rechinger, K.H. 1966g. Ebenaceae. - In: Rechinger, K.H. (ed.): Flora Iranica, Lfg. 30. Akad. Druck- und Verlagsanstalt, Graz.

Rechinger, K.H. 1966h. Elatinaceae. - In: Rechinger, K.H. (ed.): Flora Iranica, Lfg. 16. Akad. Druck- und Verlagsanstalt, Graz.

Rechinger, K.H. 1966i. Globulariaceae. - In: Rechinger, K.H. (ed.): Flora Iranica, Lfg. 17. Akad. Druck- und Verlagsanstalt, Graz.

Rechinger, K.H. 1966j. Haloragaceae. - In: Rechinger, K.H. (ed.): Flora Iranica, Lfg. 18. Akad. Druck- und Verlagsanstalt, Graz.

Rechinger, K.H. 1966k. Hippuridaceae. - In: Rechinger, K.H. (ed.): Flora Iranica, Lfg. 31. Akad. Druck- und Verlagsanstalt, Graz.

Rechinger, K.H. 19661. Myrtaceae. - In: Rechinger, K.H. (ed.): Flora Iranica, Lfg. 32. Akad. Druck- und Verlagsanstalt, Graz.

Rechinger, K.H. 1966m. Nymphaeaceae. - In: Rechinger, K.H. (ed.): Flora Iranica, Lfg. 33. Akad. Druck- und Verlagsanstalt, Graz.

Rechinger, K.H. 1966n. Phytolaccaceae. - In: Rechinger, K.H. (ed.): Flora Iranica, Lfg. 35. Akad. Druck- und Verlagsanstalt, Graz.

Rechinger, K.H. 19660. Platanaceae. - In: Rechinger, K.H. (ed.): Flora Iranica, Lfg. 21. Akad. Druck- und Verlagsanstalt, Graz. 
Rechinger, K.H. 1966p. Punicaceae. - In: Rechinger, K.H. (ed.): Flora Iranica, Lfg. 22. Akad. Druck- und Verlagsanstalt, Graz.

Rechinger, K.H. 1966q. Salvadoraceae. - In: Rechinger, K.H. (ed.): Flora Iranica, Lfg. 37. Akad. Druck- und Verlagsanstalt, Graz.

Rechinger, K.H. 1966r. Sapindaceae. - In: Rechinger, K.H. (ed.): Flora Iranica, Lfg. 38. Akad. Druck- und Verlagsanstalt, Graz.

Rechinger, K.H. 1966s. Theligonaceae. - In: Rechinger, K.H. (ed.): Flora Iranica, Lfg. 39. Akad. Druck- und Verlagsanstalt, Graz.

Rechinger, K.H. 1967a. Bignoniaceae. - In: Rechinger, K.H. (ed.): Flora Iranica, Lfg. 44. Akad. Druck- und Verlagsanstalt, Graz.

Rechinger, K.H. 1967b. Cistaceae. - In: Rechinger, K.H. (ed.): Flora Iranica, Lfg. 46. Akad. Druck- und Verlagsanstalt, Graz.

Rechinger, K.H. 1967c. Loganiaceae. - In: Rechinger, K.H. (ed.): Flora Iranica, Lfg. 45. Akad. Druck- und Verlagsanstalt, Graz.

Rechinger, K.H. 1967d. Oxalidaceae. - In: Rechinger, K.H. (ed.): Flora Iranica, Lfg. 40. Akad. Druck- und Verlagsanstalt, Graz.

Rechinger, K.H. 1969a. Anacardiaceae. - In: Rechinger, K.H. (ed.): Flora Iranica, Lfg. 63. Akad. Druck- und Verlagsanstalt, Graz.

Rechinger, K.H. 1969b. Celastraceae. - In: Rechinger, K.H. (ed.): Flora Iranica, Lfg. 64. Akad. Druck- und Verlagsanstalt, Graz.

Rechinger, K.H. 1969c. Valerianaceae. - In: Rechinger, K.H. (ed.): Flora Iranica, Lfg. 62. Akad. Druck- und Verlagsanstalt, Graz.

Rechinger, K.H. 1970. Asclepiadaceae. - In: Rechinger, K.H. (ed.): Flora Iranica, Lfg. 73. Akad. Druck- und Verlagsanstalt, Graz.

Rechinger, K.H. 1972. Compositae I: Cynareae I: Cousinia. - In: Rechinger, K.H. (ed.): Flora Iranica, Lfg. 90. - Akad. Druck- und Verlagsanstalt, Graz.

Rechinger, K.H. 1974a. Apocynaceae. - In: Rechinger, K.H. (ed.): Flora Iranica, Lfg. 103. Akad. Druck- und Verlagsanstalt, Graz.

Rechinger, K.H. 1974b. Linaceae. - In: Rechinger, K.H. (ed.): Flora Iranica, Lfg. 106. - Akad. Druckund Verlagsanstalt, Graz.

Rechinger, K.H. 1974c. Moringaceae. - In: Rechinger, K.H. (ed.): Flora Iranica, Lfg. 109. Akad. Druck- und Verlagsanstalt, Graz.

Rechinger, K.H. 1976a. Loranthaceae. - In: Rechinger, K.H. (ed.): Flora Iranica, Lfg. 116. Akad. Druck- und Verlagsanstalt, Graz.
Rechinger, K.H. 1976b. Portulacaceae. - In: Rechinger, K.H. (ed.): Flora Iranica, Lfg. 117. Akad. Druck- und Verlagsanstalt, Graz.

Rechinger, K.H. 1978a. Avicenniaceae. - In: Rechinger, K.H. (ed.): Flora Iranica, Lfg. 131. Akad. Druck- und Verlagsanstalt, Graz.

Rechinger, K.H. 1978b. Cannabaceae. - In: Rechinger, K.H. (ed.): Flora Iranica, Lfg. 138. Akad. Druck- und Verlagsanstalt, Graz.

Rechinger, K.H. 1978c. Cynomoriaceae. - In: Rechinger, K.H. (ed.): Flora Iranica, Lfg. 129. Akad. Druck- und Verlagsanstalt, Graz.

Rechinger, K.H. 1978d. Meliaceae. - In: Rechinger, K.H. (ed.): Flora Iranica, Lfg. 133. Akad. Druck- und Verlagsanstalt, Graz.

Rechinger, K.H. 1978e. Menispermaceae. - In: Rechinger, K.H. (ed.): Flora Iranica, Lfg. 137. Akad. Druck- und Verlagsanstalt, Graz.

Rechinger, K.H. 1978f. Myrsinaceae. - In: Rechinger, K.H. (ed.): Flora Iranica, Lfg. 130. Akad. Druck- und Verlagsanstalt, Graz.

Rechinger, K.H. 1978g. Pedaliaceae. - In: Rechinger, K.H. (ed.): Flora Iranica, Lfg. 128. Akad. Druck- und Verlagsanstalt, Graz.

Rechinger, K.H. 1978h. Rafflesiaceae. - In: Rechinger, K.H. (ed.): Flora Iranica, Lfg. 136. Akad. Druck- und Verlagsanstalt, Graz.

Rechinger, K.H. 1978i. Trapaceae. - In: Rechinger, K.H. (ed.): Flora Iranica, Lfg. 127. Akad. Druck- und Verlagsanstalt, Graz.

Rechinger, K.H. 1982. Sterculiaceae. - In: Rechinger, K.H. (ed.): Flora Iranica, Lfg. 156. Akad. Druck- und Verlagsanstalt, Graz.

Rechinger, K.H. 1986a. Caesalpiniaceae. - In: Rechinger, K.H. (ed.): Flora Iranica, Lfg. 160. Akad. Druck- und Verlagsanstalt, Graz.

Rechinger, K.H. 1986b. Mimosaceae. - In: Rechinger, K.H. (ed.): Flora Iranica, Lfg. 161. Akad. Druck- und Verlagsanstalt, Graz.

Rechinger, K.H. 1990a. Pontederiaceae. - In: Rechinger, K.H. (ed.): Flora Iranica, Lfg. 167. Akad. Druck- und Verlagsanstalt, Graz.

Rechinger, K.H. 1990b. Rhizophoraceae. - In: Rechinger, K.H. (ed.): Flora Iranica, Lfg. 166. Akad. Druck- und Verlagsanstalt, Graz.

Rechinger, K.H. and Lack, H.W. 1991. Dipsacaceae. - In: Rechinger, K.H. (ed.): Flora Iranica, Lfg. 168. - Akad. Druck- und Verlagsanstalt, Graz.

Rechinger, K.H. and Schiman-Czeika, H. 1964. mrbiaceae. - In: Rechinger, K.H. (ed.): Flora 
Iranica, Lfg. 6. - Akad. Druck- und Verlagsanstalt, Graz.

Rechinger, K.H. and Schiman-Czeika, H. 1965. Campanulaceae. - In: Rechinger, K.H. (ed.): Flora Iranica, Lfg. 13. - Akad. Druck- und Verlagsanstalt, Graz.

Rechinger, K.H. and Schiman-Czeika, H. 1968. Polygonaceae. - In: Rechinger, K.H. (ed.): Flora Iranica, Lfg. 56. - Akad. Druck- und Verlagsanstalt, Graz.

Rechinger, K.H. and Schiman-Czeika, H. 1974. Plumbaginaceae. - In: Rechinger, K.H. (ed.): Flora Iranica, Lfg. 108. - Akad. Druck- und Verlagsanstalt, Graz.

Rechinger, K.H., Browicz, K., Persson, K. and Wendelbo, P. 1990. Liliaceae II - In: Rechinger, K.H. (ed.): Flora Iranica 165. - Akad. Druck- und Verlagsanstalt, Graz.

Rechinger, K.H., Lack, H.W., Nordenstam, B., Pittoni, H. and van Soest, J.L. 1977. Compositae II: Lactuceae. - In: Rechinger, K.H. (ed.): Flora Iranica, Lfg. 122. - Akad. Druck- und Verlagsanstalt, Graz.

Rechinger, K.H., Melzheimer, V., Möschl, W. and Schiman-Czeika, H. 1988. Caryophyllaceae II. - In: Rechinger, K.H. (ed.): Flora Iranica, Lfg. 163. - Akad. Druck- und Verlagsanstalt, Graz.

Renz, J. 1978. Orchidaceae. - In: Rechinger, K.H. (ed.): Flora Iranica, Lfg. 126. - Akad. Druck- und Verlagsanstalt, Graz.

Riedl, H. 1963a. Araceae. - In: Rechinger, K.H. (ed.): Flora Iranica, Lfg. 3. - Akad. Druck- und Verlagsanstalt, Graz.

Riedl, H. 1963b. Ephedraceae. - In: Rechinger, K.H. (ed.): Flora Iranica, Lfg. 2. - Akad. Druckund Verlagsanstalt, Graz.

Riedl, H. 1965a. Pinaceae. - In: Rechinger, K.H. (ed.): Flora Iranica, Lfg. 14. - Akad. Druck- und Verlagsanstalt, Graz.

Riedl, H. 1965b. Taxaceae. - In: Rechinger, K.H. (ed.): Flora Iranica, Lfg. 12. - Akad. Druck- und Verlagsanstalt, Graz.

Riedl, H. 1967. Boraginaceae. - In: Rechinger, K.H. (ed.): Flora Iranica, Lfg. 48. - Akad. Druckund Verlagsanstalt, Graz.

Riedl, H. 1968. Cupressaceae. - In: Rechinger, K.H. (ed.): Flora Iranica, Lfg. 50. - Akad. Druckund Verlagsanstalt, Graz.

Riedl, H. 1969a. Paeoniaceae. - In: Rechinger, K.H. (ed.): Flora Iranica, Lfg. 60. - Akad. Druckund Verlagsanstalt, Graz.
Riedl, H. 1969b. Sparganiaceae. - In: Rechinger, K.H. (ed.): Flora Iranica, Lfg. 59. - Akad. Druckund Verlagsanstalt, Graz.

Riedl, H. 1970. Typhaceae. - In: Rechinger, K.H. (ed.): Flora Iranica, Lfg. 71. - Akad. Druck- und Verlagsanstalt, Graz.

Riedl, H. 1976a. Lemnaceae. - In: Rechinger, K.H. (ed.): Flora Iranica, Lfg. 119. - Akad. Druck- und Verlagsanstalt, Graz.

Riedl, I. 1976b. Malvaceae. - In: Rechinger, K.H. (ed.): Flora Iranica, Lfg. 120. - Akad. Druck- und Verlagsanstalt, Graz.

Robson, N.K.B. 1968. Guttiferae. - In: Rechinger, K.H. (ed.): Flora Iranica, Lfg. 49. - Akad. Druckund Verlagsanstalt, Graz.

Saeidi-Mehrvarz, Sh., Attar, F., Hamdi, S.M.M., Sharifnia, F., Assadi, M., Yousef Naanaie, S. and Mehregan, I. 2011. Scrophulariaceae. - In: Assadi, M. et al. (eds.): Flora of Iran, No. 68. - RIFR, Tehran.

Safavi, S.R. 2011. Cucurbitaceae. - In: Assadi, M. et al. (eds.): Flora of Iran, No. 70. - RIFR, Tehran.

Safavi, S.R., Naseh, E., Jafari, E., Tavakoli, Z. and Heidarnia, N. 2013. Asteraceae: Tribe Cichorieae. - In: Assadi, M. et al. (eds.): Flora of Iran, No. 77. - RIFR, Tehran.

Saghafi Khadem, F. 2000. Capparaceae. - In: Assadi, M. et al. (eds.): Flora of Iran, No. 30. RIFR, Tehran.

Salmaki, Y., Zarre, Sh., Ryding, O., Lindqvist, Ch., Scheunert, A., Bräuchler, Ch. and Heubl, G. 2012. Phylogeny of the tribe Phlomideae (Lamioideae: Lamiaceae) with special focus on Eremostachys and Phlomoides: New insights from nuclear and chloroplast sequences. - Taxon 61(1): 161-179.

Schiman-Czeika, H. 1964a. Orobanchaceae. - In: Rechinger, K.H. (ed.): Flora Iranica, Lfg. 5. - Akad. Druck- und Verlagsanstalt, Graz.

Schiman-Czeika, H. 1964b. Tamaricaceae. - In: RECHINGER K.H. (ed.): Flora Iranica, Lfg. 4. Akad. Druck- und Verlagsanstalt, Graz.

Schiman-Czeika, H. 1967. Gentianaceae. - In: Rechinger, K.H. (ed.): Flora Iranica, Lfg. 41. Akad. Druck- und Verlagsanstalt, Graz.

Schmidt, A. 1992. Violaceae. - In: Rechinger, K.H. (ed.): Flora Iranica, Lfg. 169. - Akad. Druck- und Verlagsanstalt, Graz.

Schotsman, H.D. 1976. Callitrichaceae. - In: Rechinger, K.H. (ed.): Flora Iranica, Lfg. 118. Akad. Druck- und Verlagsanstalt, Graz. 
Schönbeck-Temesy, E. 1966a. Parnassiaceae. - In: Rechinger, K.H. (ed.): Flora Iranica, Lfg. 20. Akad. Druck- und Verlagsanstalt, Graz.

Schönbeck-Temesy, E. 1966b. Vahliaceae. - In: Rechinger, K.H. (ed.): Flora Iranica, Lfg. 23. Akad. Druck- und Verlagsanstalt, Graz.

Schönbeck-Temesy, E. 1967a. Grossulariaceae. In: Rechinger, K.H. (ed.): Flora Iranica, Lfg. 47. Akad. Druck- und Verlagsanstalt, Graz.

Schönbeck-Temesy, E. 1967b. Saxifragaceae. - In: Rechinger, K.H. (ed.): Flora Iranica, Lfg. 42. Akad. Druck- und Verlagsanstalt, Graz.

Schönbeck-Temesy, E. 1970c. Geraniaceae. - In: Rechinger, K.H. (ed.): Flora Iranica, Lfg. 69. Akad. Druck- und Verlagsanstalt, Graz.

Schönbeck-Temesy, E. 1972. Solanaceae. - In: Rechinger, K.H. (ed.): Flora Iranica, Lfg. 100. Akad. Druck- und Verlagsanstalt, Graz.

Shahsavari, A. 2007. Orchidaceae. - In: Assadi, M. et al. (eds.): Flora of Iran, No. 57. - RIFR, Tehran.

Sharifnia, F. and Assadi, M. 2001. Linaceae. - In: Assadi, M. et al. (eds.): Flora of Iran, No. 34. RIFR, Tehran.

Snogerup, S. 1971. Juncaceae. - In: Rechinger, K.H. (ed.): Flora Iranica, Lfg. 75. - Akad. Druckund Verlagsanstalt, Graz.

Soufiyan, Kh. and Dinarvand, M. 2007. Rhamnaceae. - In: Assadi, M. et al. (eds.): Flora of Iran, No. 55. - RIFR, Tehran.

Taheri, Zh. 1993. Juncaceae. - In: Assadi, M. et al. (eds.): Flora of Iran, No. 10. - RIFR, Tehran.

Terminology Departmant. 2003-2015. A collection of Terms. vol 1-12. - The Academy of Persian Language and Literature, Tehran.

The International Plant Names Index. 2012 [continuously updated]. Published on the Internet: http://www.ipni.org (accessed 10 May 2016).

The Plant List. 2013 [continuously updated]. Version 1.1. Published on the Internet: http://www.theplantlist.org/ (accessed 10 May 2016).

Thiers, B. 2016 [continuously updated]. Index herbariorum: A global directory of public herbaria and associated staff. New York Botanical Garden, Bronx, NY. Available from: http://sweetgum.nybg.org/ih/ (accessed 10 March 2016).

Thiv, M. 2016. Vahliaceae. - In: Kubitzki, K. (ed.): The families and Genera of vascular plants, Vol. XIV. - Springer, Switzerland. p: 381.
Townsend, C.C. 1966. Rutaceae. - In: Rechinger, K.H. (ed.): Flora Iranica, Lfg. 36. - Akad. Druckund Verlagsanstalt, Graz.

Vassilczenko, L.T. 1970. Vitaceae. - In: Rechinger, K.H. (ed.): Flora Iranica, Lfg. 74. Akad. Druck- und Verlagsanstalt, Graz.

Wendelbo, P. 1965a. Caprifoliaceae. - In: Rechinger, K.H. (ed.): Flora Iranica, Lfg. 10. Akad. Druck- und Verlagsanstalt, Graz.

Wendelbo, P. 1965b. Ericaceae. - In: Rechinger, K.H. (ed.): Flora Iranica, Lfg. 11. - Akad. Druckund Verlagsanstalt, Graz.

Wendelbo, P. 1965c. Primulaceae. - In: Rechinger, K.H. (ed.): Flora Iranica, Lfg. 9. - Akad. Druckund Verlagsanstalt, Graz.

Wendelbo, P. 1968. Hamamelidaceae. - In: Rechinger, K.H. (ed.): Flora Iranica, Lfg. 53. Akad. Druck- und Verlagsanstalt, Graz.

Wendelbo, P. 1970. Amaryllidaceae. - In: Rechinger, K.H. (ed.): Flora Iranica, Lfg. 67. Akad. Druck- und Verlagsanstalt, Graz.

Wendelbo, P. 1971. Alliaceae. - In: Rechinger, K.H. (ed.): Flora Iranica 76. - Akad. Druck- und Verlagsanstalt, Graz.

Wendelbo, P. 1973. Dioscoreaceae. - In: Rechinger, K.H. (ed.): Flora Iranica, Lfg. 104. Akad. Druck- und Verlagsanstalt, Graz.

Wendelbo, P. 1974. Fumariaceae. - In: Rechinger, K.H. (ed.): Flora Iranica, Lfg. 110. - Akad. Druckund Verlagsanstalt, Graz.

Wendelbo, P. 1982. Liliaceae I. - In: Rechinger, K.H. (ed.): Flora Iranica, Lfg. 151. - Akad. Druckund Verlagsanstalt, Graz.

Yousef Naanaie, S. 2010. Lythraceae. - In: Assadi, M. et al. (eds.): Flora of Iran, No. 67. - RIFR, Tehran.

Yuncker, T.G. and Rechinger, K.H. 1964. Cuscutaceae. - In: Rechinger, K.H. (ed.): Flora Iranica, Lfg. 8. - Akad. Druck- und Verlagsanstalt, Graz.

Zaeifi, M. 1995. Mimosaceae. - In: Assadi, M. et al. (eds.): Flora of Iran, No. 18. - RIFR, Tehran.

Zaeifi, M. 2000. Asclepiadaceae. - In: Assadi, M. et al. (eds.): Flora of Iran, No. 28. - RIFR, Tehran.

Zaeifi, M. 2016a. Avicenniaceae. - In: Assadi, M. et al. (eds.): Flora of Iran, No. 78. - RIFR, Tehran.

Zaeifi, M. 2016b. Rhizophoraceae. - In: Assadi, M. et al. (eds.): Flora of Iran, No. 80. - RIFR, Tehran.

Zaeifi, M. 2016c. Salvadoraceae. - In: Assadi, M. et al. (eds.): Flora of Iran, No. 79. - RIFR, Tehran. 
Zare, H. 2016. Betulaceae. - In: Assadi, M. et al. (eds.): Flora of Iran, No. 84. - RIFR, Tehran.

Zarre, Sh., Maassoumi, A.A. and Podlech, D. 2008. Papilionaceae V, Astragalus III. - In: Rechinger K.H. (ed.): Flora Iranica, Lfg. 177. Naturhistorisches Museum, Wien.
Zielinski, J. 1979. Ulmaceae. - In: Rechinger, K.H. (ed.): Flora Iranica, Lfg. 142. - Akad. Druck- und Verlagsanstalt, Graz.

Zielinski, J. 1982. Rosaceae II. - In: Rechinger, K.H. (ed.): Flora Iranica, Lfg. 152. - Akad. Druckund Verlagsanstalt, Graz.

Ghahremaninejad, F. and Nejad Falatoury, A. 2016. An update on the flora of Iran: Iranian angiosperm orders and families in accordance with APG IV. - Nova Biol. Rep. 3: 80-107.

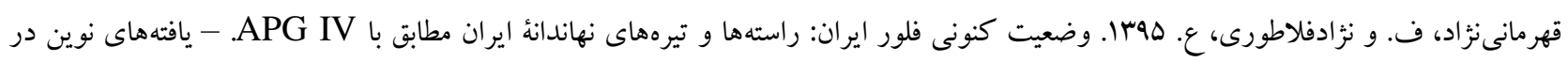

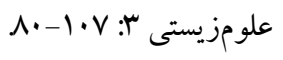

